WALDEN

UNIVERSITY

A higher degree. A higher purpose.

Walden University ScholarWorks

2018

\title{
Counselors' Knowledge and Attitudes of the Recovery Paradigm
}

Kathleen Ruscitto

Walden University

Follow this and additional works at: https://scholarworks.waldenu.edu/dissertations

Part of the Adult and Continuing Education Administration Commons, Adult and Continuing Education and Teaching Commons, and the Psychiatric and Mental Health Commons

This Dissertation is brought to you for free and open access by the Walden Dissertations and Doctoral Studies Collection at ScholarWorks. It has been accepted for inclusion in Walden Dissertations and Doctoral Studies by an authorized administrator of ScholarWorks. For more information, please contact ScholarWorks@waldenu.edu. 


\title{
Walden University
}

College of Counselor Education \& Supervision

This is to certify that the doctoral dissertation by

\author{
Kathleen Ruscitto
}

has been found to be complete and satisfactory in all respects, and that any and all revisions required by the review committee have been made.

\author{
Review Committee \\ Dr. Corinne Bridges, Committee Chairperson, Counselor Education and Supervision \\ Faculty \\ Dr. Melinda Haley, Committee Member, Counselor Education and Supervision Faculty \\ Dr. Michelle Perepiczka, University Reviewer, Counselor Education and Supervision \\ Faculty
}

Chief Academic Officer

Eric Riedel, Ph.D.

Walden University

2018 


\author{
Abstract \\ Counselors' Knowledge and Attitudes of the Recovery Paradigm \\ by \\ Kathleen Ruscitto
}

MA, Waynesburg University, 2010

BA, La Roche College, 2008

\begin{abstract}
Proposal Submitted in Partial Fulfillment
of the Requirements for the Degree of

Doctor of Philosophy

Counselor Education and Supervision
\end{abstract}

Walden University

November 2018 


\begin{abstract}
As of 2014 , an estimated $18.1 \%$ or approximately 43.6 million adults, 18 years of age or older in the United States experienced a form of mental illness. Professional counselors subscribe to a wellness or holistic paradigm; however the recovery paradigm, using collaborative strategies and unique treatment planning is the directed approach of mental health services in the United Stated. The purpose of this quantitative study was to understand what factors contribute to counselors' knowledge and attitudes of the recovery paradigm. Survey methodology was used to examine whether, among professional counselors, years of experience, gender, professional setting, and licensure status, as measured by a demographic questionnaire, correlate to professional counselors' (a) attitudes and level of knowledge of the recovery paradigm, (b) knowledge and attitudes of the roles and responsibilities in recovery, (c) understanding and attitudes toward the personal journey of the recovery process, (d) knowledge and attitudes of the roles of self-identity and peer support in recovery, and (e) knowledge and attitudes of the expectations regarding recovery as measured by the 4 subscales of the Recovery Knowledge Inventory (RKI). The target population was 225 masters or doctoral level counselors. The results of a multivariate multiple regression were not significant. However, the results of this study align with previous research outcomes indicating a need for counselors continued education and training on the recovery paradigm which could improve their knowledge and attitudes of the recovery paradigm, directly impacting consumers' achievement of recovery goals.
\end{abstract}


Counselors' Knowledge and Attitudes of the Recovery Paradigm by

Kathleen Ruscitto

MA, Waynesburg University, 2010

BA, La Roche College, 2008

\begin{abstract}
Proposal Submitted in Partial Fulfillment
of the Requirements for the Degree of

Doctor of Philosophy

Counselor Education and Supervision
\end{abstract}

Walden University

November 2018 


\section{Acknowledgments}

I would like to thank the members of my committee. First of all, my chair, Dr. Corinne Bridges your guidance, endless patience, and genuine respect for me has been unforgettably inspiring. I would also like to thank the second member of my committee and my methodologist, Dr. Melinda Haley, for your expertise and knowledge, helping me interpret and finalize my study. To the URR of my committee, Dr. Michelle Perepiczka, thank you for offering your feedback and professional insights.

To my friend and mentor, Anne Shaffer, for being a support and inspiration. To my husband, for being a rock and having patience while I perused my dreams. Finally, to my family and friends, for cheering me on through this journey, I am grateful to have you in my life. 


\section{Table of Contents}

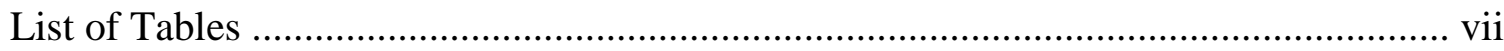

List of Figures .................................................................................................viii

Chapter 1: Introduction to the Study ...................................................................

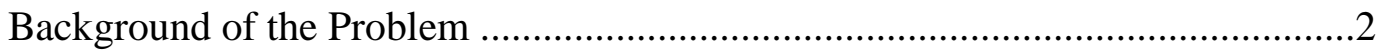

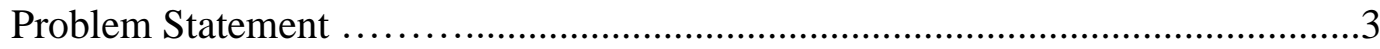

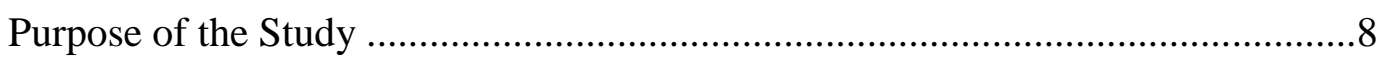

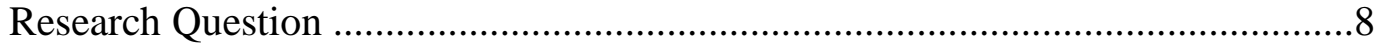

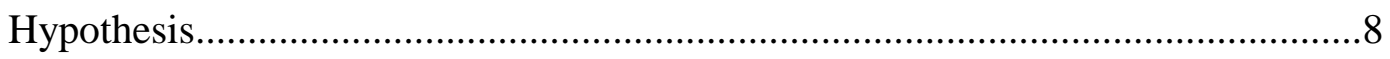

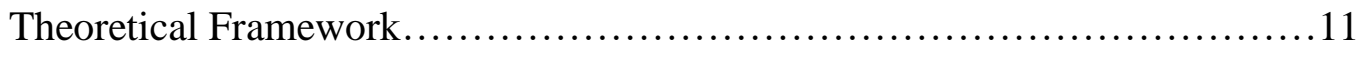

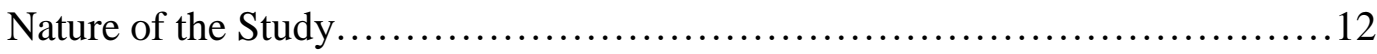

Definitions...................................................... 14

Assumtions......................................................... 15

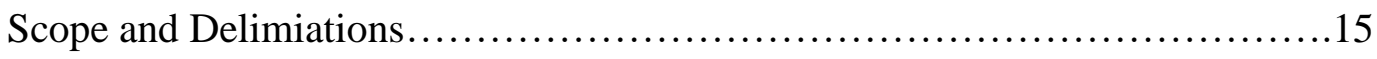

Limitations.................................................... 16

Significance.................................................... 17

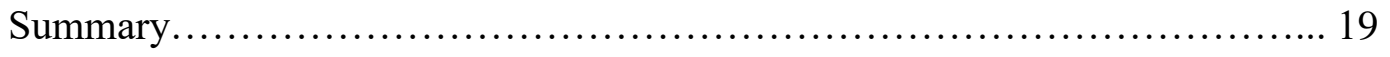

Chapter 2: Literature Review..............................................20

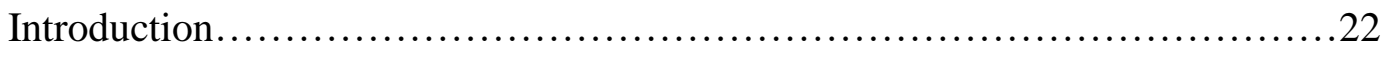

Literature Search Strategy...........................................22

Theoretical Framework................................................23

Literature Review..................................................23 


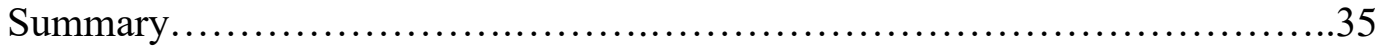

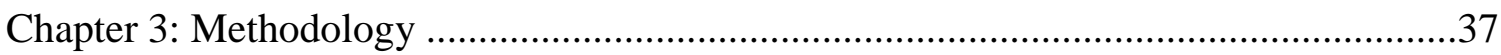

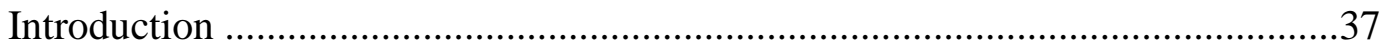

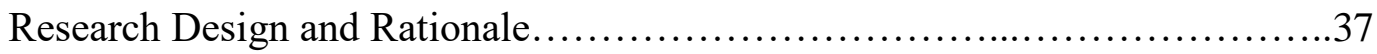

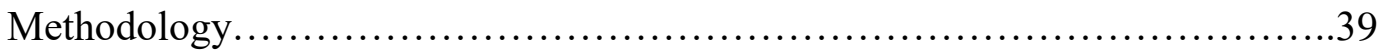

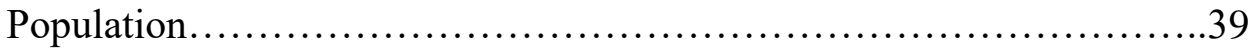

Sampling and Sampling Procedure ......................................39

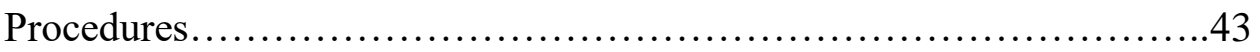

Instrumentation and Operationalization of Constructs..................44

Data Analysis Plan................................................ 47

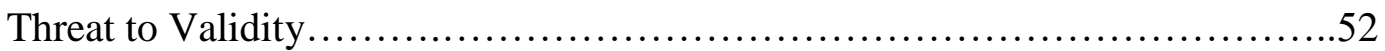

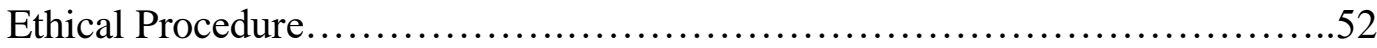

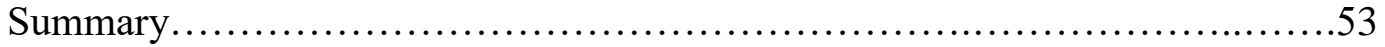

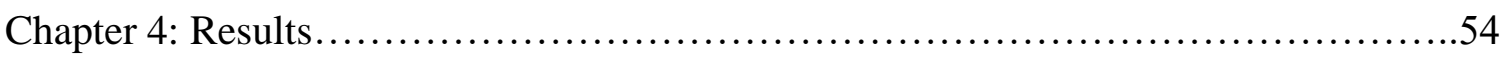

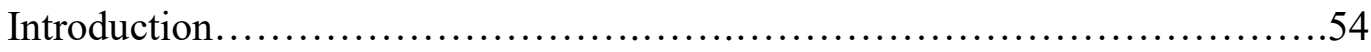

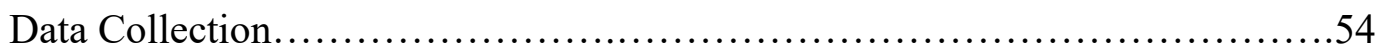

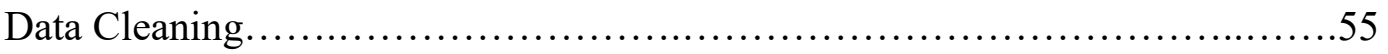

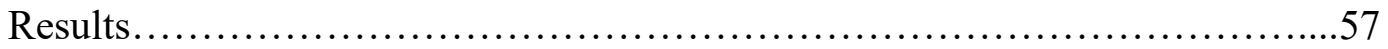

Characteristics of the Study Participants.................................57

Mean and Standard Deviation of the Dependent Variables................59

Multiple Regression Analysis........................................60

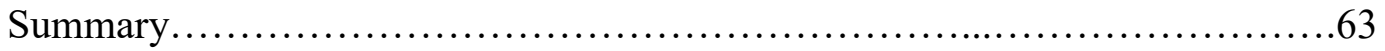


Chapter 5: Discussion, Conclusions, and Recommendations........................64

Introduction.....................................................64

Interpretations of the Findings......................................64

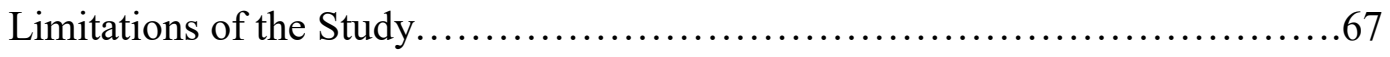

Recommendations...............................................69

Implications....................................................... 70

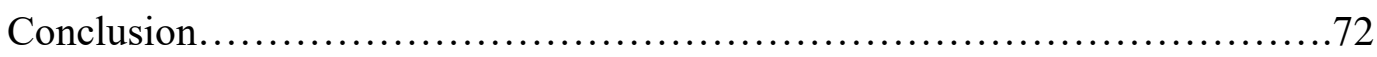




\section{List of Tables}

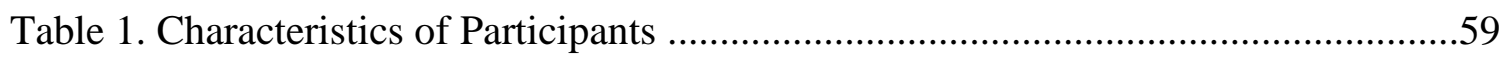

Table 2. Mean and Standard Deviation of the Dependent Variables ............................. 60

Table 3. Multivariate Test= Wilks' Lamba .............................................................61

Table 4. Test between Subjects..........................................62 
Chapter 1: Introduction to the Study

\section{Introduction}

Recovery is strength-based which empowers individuals to take control and direct their lives. Recovery is hope, empowerment, support, education, self-help, spirituality, and meaningful activity (SAMHSA, 2014). The psychiatric rehabilitation model emerged in the United States during the 1960's and 1970's in combination with the deinstitutionalization of patients with mental illness from psychiatric facilities. The psychiatric rehabilitation model served as a new model of treatment for individuals with serious mental illness (SMI; Farkas, Anthony, \& Cohen, 1989; Farkas \& Anthony, 2010). Counselors' knowledge and application of recovery-oriented care and psychiatric rehabilitation are essential to mental health best practices. A 2003 report by The New Freedom Commission on Mental Health recognized the recovery paradigm as best practice in the delivery of mental health services (Hogan, 2003). Historically, counselors have followed the wellness paradigm, a holistic paradigm that offers a philosophical base for counselors. The wellness paradigm offers counselors a unique approach to the treatment of mental health concerns. (Myers, 1992; Myers \& Sweeney, 2008; Roscoe, 2009), which has left counselors absent from recovery-oriented research. Despite similarities between the two paradigms, mental health professionals cannot assume that counselors hold the same attitudes and knowledge about recovery and psychiatric rehabilitation as other professionals within the helping field.

In this chapter, I present the background for my study, the problem that I addressed, the literature that was relevant to my topic, and my research hypotheses and 
questions. Additionally, I discuss the conceptual framework of the recovery model. I include a discussion on the nature and design of my study, the definition of the terms used in the study, the assumption, delimitations, limitations, and the potential significance of my research. I conclude this chapter with a summary.

\section{Background}

The APA (2014) defines SMI in the Diagnostic and Statistical Manual (DSM-5) as a mental or emotional disorder, excluding developmental and substance disorders. Adults with SMIs must experience symptoms within a 12-month period, and the symptoms must cause significant impairment in the daily life of the affected (American Psychiatric Association, 2013). SMIs include major depression, bipolar disorder, schizophrenia, and other mental disorders that are serious in nature (SAMHSA, 2014).

After years of research and grassroots movements, The New Freedom Commission (NFC) was formed in 2003 to assess the United States mental health treatment needs and delivery system (NFC, 2003). Their findings called for the transformation of the United States mental health system focused on consumer consumercentered care, and thus the recovery paradigm became the directed approach to mental health treatment within the United States (NFC, 2003). Counselors traditionally follow the wellness paradigm a holistic paradigm that offers a philosophical base for counselors. The wellness paradigm offers counselors a unique approach to the treatment of mental health concerns. (Hattie et al.,2014; Myers,1992; Myers et al., 2000; Myers, \& Sweeney, 2004; Myers \& Sweeney, 2008; Roscoe, 2009). Although the wellness paradigm and the recovery paradigm are health-centered rather than disease-centered and emphasize the 
role of the consumer in obtaining health and well-being, the two paradigms remain distinct from one another (Sterling et al., 2010). It is not clear what counselors' knowledge and attitudes are toward the recovery paradigm. Recently, researchers (e.g. Berry \& Greenwood, 2015; Wilrycx, et al., 2015) have sought to discover how mental health professionals can better support the process of recovery from mental illness while recognizing both the positive and negative effects that professionals can have on the process of recovery. Both the relationship between the consumer and the counselor, and the use of recovery strategies such as collaboration and unique treatment planning that mental health professionals use when working with consumers are associated with the positive and/or negative outcomes of consumer recovery (Berry \& Greenwood, 2015; Moran et al., 2014; Wilrycx, et al., 2015). As recovery is the directed approach of mental health treatment within the United Stated under the NFC, the literature includes other mental health professionals such as social workers (Carpenter ,2002; Clearly \& Dowling, 2009; Scheyett, DeLuca, \& Morgan, 2009), psychiatrists (Peebles et al.,2009; Razzano et al., 2010; Stratford, Brophy, \& Castle,2012), and psychologists (Clearly\& Dowling, 2009; Peebles et al.,2009; Reddy, Spauldin, Jansen, Menditto, \& Pickett, 2010). This study fills in the gap of the existing literature to include counselors in the research on the topic of the recovery paradigm.

\section{Problem Statement}

Morbidity and mortality are higher in those who have SMIs (Chronister, Chou, \& Liao, 2013; Sickels, Nabors, \& Seacat, 2014). Isolation, stigma, and difficulties with illness management are also common associations with those who experience SMIs 
(Chronister, Chou, \& Liao, 2013; Sickels, Nabors, \& Seacat, 2014). The death rate for individuals with SMI such as bipolar disorder and schizophrenia are 2.22 times higher compared to the general population. (Price et al., 2016; Woodhead, Ashworth, Schofield, \& Henderson, 2014).

Harding, Brooks, Asgikga, Strauss, and Breier (1986) and Tsuang, Woolson, and Fleming (1979) found most individuals with mental illness could recover and lead full and active lives. According to Moran and Russo-Netzer (2016), recovery is:

a deeply personal, unique process of changing one's attitudes, values, feelings, goals, skills and/or roles. It is a way of living a satisfying, hopeful, and contributing life even with limitations caused by the illness. Recovery involves the development of new meaning and purpose in one's life as one grows beyond the catastrophic effects of mental illness. (p. 273)

Mental health activists of the 1970s defined themselves and anyone who received mental health services or anyone who had a diagnosis of mental illness as a consumer (McLaughlin, 2009). It was the consumer movement that simultaneously occurred with the publication of new research that demonstrated mental health recovery that was the most influential in the development of a mental health recovery model (Peebles et al., 2009). These movements and publication by the activists of the 1970 s brought national awareness for the need of a systematic change of then mental health delivery system within the United States (Ostrow \& Adams, 2012).

The recovery paradigm became the directed approach of mental health services within the United States in 2003, a change from a traditional perspective of symptom 
reduction and improvement in functioning through psychiatry (NFC,2003; Ostrow \& Adams, 2012; The President's New Freedom Commission on Mental Health, 2003). The shifts in policies have been informed by the consumer perspective (Ostrow \& Adams, 2012). Additionally, the recovery paradigm challenges professionals to join in partnership with consumers and their families to create a culture of recovery and empowerment and to act as social change agents creating new opportunities for consumers on all platforms (Barton, 1998).

The literature contains studies about mental health recovery and the knowledge and attitudes of mental health professionals including social workers (Carpenter ,2002; Clearly \& Dowling, 2009; Scheyett, DeLuca, \& Morgan, 2009), psychiatrists (Peebles et al.,2009; Razzano et al., 2010; Stratford, Brophy, \& Castle,2012), psychologists (Clearly\& Dowling, 2009; Peebles et al.,2009; Reddy, Spauldin, Jansen, Menditto, \& Pickett, 2010), and counselors (Crowe et al., 2013). Clearly and Dowling's (2009) study found that nurses, doctors, social workers, occupational therapists, and psychologists indicated an adoption of the recovery model in the delivery of professional services; however, the nurses, doctors, social workers, occupational therapists, and psychologists were limited in their knowledge of essential aspects of recovery. The authors highlight the need to equip mental health professionals with recovery skills and information through education and training.

Carpenter (2002) suggested that the values and beliefs of the recovery movement through the recovery paradigm align with those of the social work profession. Furthermore, the values and concepts of the recovery paradigm are reflected in social 
workers' direct practice, education, administration, and research. Through the alignment with the recovery paradigm, social workers are in a unique position to support consumers and develop system change. Crowe et al. (2013) measured the knowledge, attitudes, and confidence/competence of counselors in a 12-month internship program designed to train counselors on the recovery paradigm. The Recovery Knowledge Inventory (RKI) was one of the tools used to measure the knowledge and attitudes toward recovery-oriented counseling practices (Crowe et al., 2013). The researchers found significant increases in counselors' knowledge, attitudes, and confidence/competence post internship (Crowe et al., 2013). The absence of similar studies with counselors is a gap in the literature that is addressed through this study.

The RKI was developed to measures the knowledge and attitudes of professional ethics in terms of role and responsivity in recovery, nonlinearity of the recovery process, the role of self and peers in recovery, and expectation about recovery (Bedregal et al., 2016). Researchers use the RKI to assess training needs of professionals who provide recovery-oriented care. Increasing knowledge and attitudes of recovery will enhance recovery-oriented care.

There is a continued discussion about how mental health professionals can support consumer recovery, as mental health professionals can have positive or negative effects on consumer recovery (Berry \& Greenwood, 2015; Wilrycx, et al., 2015). The symptoms of thought disorders such as schizophrenia or mood disorders such as bipolar can impede therapeutic relationships (Cavelti et al., 2016). To support consumer recovery, mental health professionals must be knowledgeable in inspiring hope and 
empowerment in consumers (Cavelti, Homan, \& Vauth, 2016; Green et al., 2008;

Wilrycx, et al., 2015). Researchers have shown a positive correlation between recoveryoriented consumer-focused care and consumer engagement, satisfaction, symptom reduction, and greater attained recovery and quality of life (Green et al., 2008).

Counselors subscribe to the wellness paradigm (Myers, 1992; Myers \& Sweeney, 2008; Roscoe, 2009). The wellness paradigm is rooted in psychology (Schueller, 2009). The promotion of wellness to improve human life was recognized as early as the turn of the 20th century (Schueller, 2009). Humanistic psychologists such as Maslow and Rogers reflected this perceptive and argued that psychologists needed to help people achieve their full potential (Schuller, 2009). Carl Rogers was the first to use the term "client" as part of the humanistic approach to move away from viewing the psychologist as the specialist and focusing on the congruence of the counseling relationship (Cooper \& McLeod, 2011). A humanistic approach requires the client to take an active role in his or her treatment (Cooper \& McLeod, 2011).

The wellness and recovery paradigms are distinct yet interrelated concepts that have gained an increasing amount of attention and research as they apply to consumers and community mental health providers (Sterling, von Esenwein, Ticker, Fricks, \& Dress, 2010). The wellness paradigm originates from alternative medicine while the recovery paradigm originates from the consumer movement (Sterling et al., 2010). Both paradigms focus on health versus disease and emphasize the role of the consumer/client in the management of their health (Sterling et al., 2010). Wellness and recovery are also connected by the shared dimensions of holism, patient-centeredness, and nonlinearity 
(Sterling et al., 2010). Despite similarities, each concept is complex and defined differently by the various stakeholder groups (Sterling et al., 2010). Therefore, it was necessary to study counselors' knowledge of and attitudes toward the recovery paradigm to fill the gap in the existing literature.

\section{Purpose of the Study}

The purpose of this quantitative study was to understand what demographics of counselors' correlate to counselors' knowledge and attitudes of the recovery paradigm through survey research methodology. Achieving recovery is rooted in recovery-oriented care and services between all stakeholders which includes but is not limited to the consumer, community supports, family members, and mental health providers (Ostrow \& Adams, 2012). Counselors, like social workers, psychiatrists, and psychologists, are vital stakeholders of the recovery paradigm. I examined the relationship between the independent variables of gender, years of experience, practice setting, and licensure status and the dependent variable of counselors' knowledge and attitudes of recovery practices. I used an online survey that included the use of the Recovery Knowledge Inventory (Bedregal, O'Connell \& Davidson, 2006) to measure the four domains of understanding. I used demographic information questions to measure the independent variables.

\section{Research Question and Hypothesis}

Kidd, Kenny, and McKinstry (2015) and Stanhope et al. (2015) suggested that professional attitudes toward consumer recovery greatly influence recovery outcomes. Both the wellness paradigm and the recovery paradigm are health-centered rather than disease-centered and emphasize the role of the consumer in obtaining health and well- 
being (Sterling, von Esenwein, Ticker, Fricks, \& Dress, 2010). I examined the following research question:

Research Question 1 (RQ1): Among professional counselors, does years of experience, gender, professional setting, and licensure status, as measured by a demographic questionnaire, correlate to professional counselors' (a) attitudes and level of knowledge of the recovery paradigm, (b) knowledge and attitudes of the roles and responsibilities in recovery, (c) understanding and attitudes toward the personal journey of the recovery process, (d) knowledge and attitudes of the roles of self-identity and peer support in recovery, and (e) knowledge and attitudes of the expectations regarding recovery as measured by the four subscale of the RKI.

H0 Is there a statistically significant relationship between counselors' years of experience, gender, professional setting, and licensure status as measured by a demographic survey and counselors' knowledge and attitudes of the roles and responsibilities in recovery as measured by the RKI

Ha There is no statistically significant relationship between a regression model including years of experience, gender, professional setting, and licensure status as measured by a demographic survey and counselors' knowledge and attitudes of the roles and responsibilities in recovery as measured by RKI.

H0 Is there a statistically significant relationship between a regression model including years of experience, gender, professional setting, and licensure status as measured by a demographic survey and counselors' understanding and attitudes towards the personal journey of the recovery process as measured by RKI. 
Ha There is no statistically significant relationship between a regression model including years of experience, gender, professional setting, and licensure status as measured by a demographic survey and counselors' understanding and attitudes towards the personal journey of the recovery process as measured by RKI.

H0 Is there a statistically significant relationship between a regression model including years of experience, gender, professional setting, and licensure status as measured by a demographic survey and counselors' knowledge and attitudes of the roles of self-identity and peer support in recovery as measured by RKI.

Ha There is no statistically significant relationship between a regression model including years of experience, gender, professional setting, and licensure status as measured by a demographic survey and counselors' knowledge and attitudes of the roles of self-identity and peer support in recovery as measured by RKI.

$\mathrm{H} 0$ Is there a statistically significant relationship between a regression model including years of experience, gender, professional setting, and licensure status as measured by a demographic survey and counselors' knowledge and attitudes of the expectations regarding recovery as measured by RKI.

Ha There is no statistically significant relationship between a regression model including years of experience, gender, professional setting, and licensure status as measured by a demographic survey and counselors' knowledge and attitudes of the expectations regarding recovery as measured by RKI.

The nature of this study was quantitative and I used RKI. Participants held a master's or doctoral degree in counseling with a specialization in mental health 
counseling and addiction counseling. Participants worked in the community setting (community practice, private practice, hospital, or other community-oriented service providers). I created a Demographics Information Questionnaire (DIO) to understand the demographics of participants. I used the RKI (Bedregal et al.,2006) to measure counselors' knowledge of and attitudes toward recovery practices on four subscales (roles and responsibilities, the nonlinearity of recovery, roles and self-definition of peers in recovery, expectation regarding recovery). There American Counseling Association (ACA), Counselor Educator and Supervisor Network Listserv (CESNET-L), identified counseling networking groups through Facebook (Professional Mental Health Counselors, Social Workers, \& Psychologists, Action Research Network, Mental Health Counselors Networking Group, Online Counseling Referral Network, Counselor/Therapist Networking/Consultation Group) were used to identify participants.

\section{Theoretical Framework}

The recovery model supports collaboration, a working partnership between consumers and stakeholders, and consumer choice (Kidd, Kenny, \& McKinstry, 2015). The recovery model promotes the idea that with hope, meaning, and purpose in life, people with serious mental illness can and do recover (Farkas, Anthony, \& Cohen, 1989; Farkas \& Anthony, 2010; SAMHSA,2014). The model states that a consumer needs to create a sense of self aside from their mental illness, develop self- agency, find hope and support through professional and personal relationships, and improve their role functions through actives such as employment, education, parenthood, etc. (Mancini, 2008). The literature suggests that professional attitudes toward recovery greatly influence recovery 
outcomes (Kidd et al.,2015; Stanhope et al., 2015). Key factors of the recovery model parallel many of those in the wellness model (Sterling, et al.,2010). The preamble of the ACA code of ethics and the professional values which counselors follow outlines the need for counselors to enhance and foster autonomous consumer development (ACA, 2014, p.3). To do this, counselors train in person-centered counseling that uses evidenced-based intervention; however, research does not include counselors' knowledge and attitudes towards consumer recovery. Chapter 2 includes further discussion about the recovery model as the framework for this study.

\section{Nature of the Study}

I used a quantitative research method for this study. The research design was nonexperimental. To achieve my sample size, I ran the power for an MANOVA using G*Power software. I chose a two-tailed test and a medium effect size of .5, as Field (2013) stated that these are most commonly used in the social sciences. The statistical test was set MANOVA: Global Effects. Additionally, the x error will be set to .05 and the statistical power to .95 , both commonly accepted in the social sciences (Fields, 2013). I determined that the required sample size of at least 186 participants.

I used convenience sampling for this study which included a population of masters and doctoral level counselors. I used surveys to collect my data. I used the RKI (Bedregal, O’Connell \& Davidson, 2006) and the Demographics Information Questionnaire (DIO) to collect data from participants. The RKI provides participants with the ability to self-report on four subscales (roles and responsibilities, the nonlinearity of recovery, roles and self-definition of peers in recovery, expectation regarding recovery). I 
used the DIQ to collect data on participants' years of experience, gender, practice setting, and licensure status. I invited participants to complete an online survey via SurveyMonkey. I identified the independent variables as the demographic variable (participants years of experience, gender, practice location, licensure status). I identified the dependent variables as the four subscales of the on the RKI (roles and responsibilities, the nonlinearity of recovery, roles and self-definition of peers in recovery, expectation regarding recovery).

I determined that a quantitative research method and data collection method as appropriate for this study, as the methods would all me to answer my research questions through a survey instrument that measures the participants knowledge and attitudes toward recovery. A qualitative or experimental design is not appropriate as the designed would not have answered my research question. For example, I would use a qualitative design to explore a phenomenon as outlined by Creswell (2009) and Frankfort-Nachmias and Nachmias (2008); however, this is not they goal for my study. Researchers use a quantitative study to examine research questions and hypotheses with statistical outcomes and associations between variables (Creswell,2009). My goal for this study was to explore the factors that contribute to counselors' knowledge and attitudes of the recovery paradigm as measured through a demographic's questionnaire and the four subscales of the RKI. I rejected other research designs as I would not have been able to examine the relationship between the study variables as a cross-sectional design does. Therefore, I found a cross-sectional design as the most appropriate for this study. 


\section{Definitions of Terms}

The following are the definitions of key terms that I used in this study.

American Counseling Association (ACA): Is the world's largest association representing professional counselors in various practice settings (ACA, 2017).

Client: "an individual seeking or referred to the professional services of a counselor" (ACA, 2014, p.20).

Consumer: This term refers to an individual who is currently receiving or has received services for a mental health diagnosis (Kaufman et al., 2011).

Counselor: Are individuals who develop professional relationships with others that empower diverse individuals, families, and groups to accomplish mental health, wellness, education, and career goals (CACREP, 2017).

Counselor competency: According to the ACA (2014) "Code of Ethics", is important for counselors to gain competence in the areas of counseling that they provide to the ones they serve. The ACA (2014) "Code of Ethics", Section C.2.a. Boundaries of Competence stated counselors should practice only within their boundaries of competence based on their education, training, state and national credentials, and professional experience.

Mental Health Professionals: An interdisciplinary counseling profession that is community based and comprehensive. Mental health includes an emphasis on development, environment, prevention, and treatment issues (Gladding, 2001, p. 74). 
Recovery Knowledge Inventory (RKI): Is a scale that assesses mental health

professionals' knowledge and attitudes toward recovery-oriented practices that are used in mental health and substance abuse treatment and rehabilitation services (Bedregal, 2006).

recovery paradigm: The individuated process in which consumers overcome and find new meaning and purpose in their lives that goes beyond the effects of mental illness (Anthony, 1993).

Wellness Paradigm: Wellness refers to the maximizing of human potential through positive life-style choices.: (Myers, 1991).

\section{Assumptions}

I requested the participation of counselors' who meet the specific criteria that includes: possessing a master's degree in counseling and a minimum of one year of professional experience post-graduation, and those who are either licensed and nonlicensed counselors. The survey consisted of questions that investigate the knowledge and attitudes of the recovery paradigm and consumer recovery. Therefore, an assumption of this study included the belief that counselors would answer the survey questions honestly. I took precautions to preserve anonymity and confidentiality of the participants through an online survey. Participation was voluntary, and participants could have withdrawn from the study at any time without penalty.

\section{Scope and Delimitations}

Through this study, I sought to understand counselor knowledge and attitudes of mental health recovery. Understanding counselors' knowledge and attitudes of mental 
health recovery could support future research, training, and the clinical practice of counselors. Delimitations or factors that narrowed the focus in this research study included the following:

I chose to include only self-identified counselors who held a masters or doctoral degree in counseling and had a minimum of 1 year of experience post-graduation. I chose to exclude counselors who identified themselves as social workers, psychologists, case workers, and marriage and family therapists as their expertise differs from counselors and would not adequately represent the study population.

This study was delimited to counselors who have Internet access. This study was delimited to counselors with access to email and membership in the American Counseling Association (ACA), the Counselor Educator and Supervisor Network Listserv (CESNET-L), or counseling networking groups through Facebook (Professional Mental Health Counselors, Social Workers, \& Psychologists, Action Research Network, Mental Health Counselors Networking Group, Online Counseling Referral Network, Counselor/Therapist Networking/Consultation Group). This delimitation does create barriers to a representative sample as it would not include counselors who chose not to hold membership in these organization; however, the sample that was obtained from these organizations does provide representation of the demographic variables to generalize this study.

\section{Limitations}

Limitations of this study include generalizability, accessibility, time constraints, and the type of inquiry. Generalizability is the expansion of research finding from a study 
sample to the larger population (Frankfort-Nachimas \& Nachmias, 2008). One way to increase the probability of generalizability in a quantitative survey is to increase the sample size. A second way to increase generalizability is through the representativeness of the participants. Additionally, internal validity is also important in reducing the limitation of generalizability (Frankfort-Nachimas \& Nachmias, 2008). This study possesses the potential for the limitation of generalizability and steps will be implemented to resolve the limitation. Counselors that participated in this study needed access to a computer and the Internet. Furthermore, participants also needed to possess basic technology skills to complete the online survey. Participants consisted of a selfselected sample. The population itself can affect the response rates to the online survey. Online surveys use self-reported measures to develop conclusion about the study population (Field, 2013). The halo effect is a concept that suggests that study participants will respond to survey question in a way they believe is socially desirable and socially expected (Creswell, 2009). The quantitative inquiry is a limit as quantitative research cannot obtain in-depth understanding about the lived experiences of participants as a qualitative method can (Creswell, 2009). Time constraints are a noted limitation what online surveys are used to obtain participants (Field, 2013). Response rates can be low; therefore, it may take more time to obtain required sample sizes.

\section{Social Change}

The results of this study contributed to the gap in counseling research by providing insights into counselors' knowledge and attitudes of recovery principles that research shows can have positive or negative impacts on consumers' achievement of 
personal recovery and quality of life (Berry \& Greenwood, 2015; Wilrycx, et al., 2015). A previous study by Moran et al., (2014) indicated the working alliance and mental health professionals' recovery strategies were positively associated with recovery. The more the consumer perceived the professional as using recovery strategies, the more the consumer perceived a working alliance and the more consumer consumers sense of recovery increased. Social inclusion is a multi-dimensional mental health construct (Berry \& Greenwood, 2015). Social inclusion is central to personal recovery, which includes the need for social activity, occupational activity, and a personal sense of belonging. Berry and Greenwood's (2015) study indicated a positive association between hope-inspiring therapeutic relationship and social inclusion. Furthermore, hope is a tenet of the recovery paradigm. A developed understanding of recovery will transform the mental health system (Slade et al., 2014). Effective treatment occurs when practitioners have a correct understanding of what recovery means. Mental health treatment is helpful in consumer recovery; however, treatment can hinder recovery when it is associated with flawed practices.

The study is unique as the wellness paradigm is traditionally taught and followed by counselors who practice their skills in communities which is the overarching paradigm within the United States. In addition, after a thorough examination of the literature, I have been unable to identify any research conducted on the research topic with counselors although research including multiple closely related fields is available. Counselor competency is a professional responsibility of all counselors (ACA, 2014). The results of this study could influence counseling education, training, and practices. These potential 
influences will create positive social change that has directed impact to the consumers' attainment of personal recovery and the highest quality of life.

\section{Summary}

In this quantitative research study, I explored counselors' knowledge and attitudes of recovery. Studying counselors' knowledge and attitudes of recovery have many potential benefits for the counseling professions. For example, these benefits may include increased awareness of counselors' perceived competencies of recovery, increased ethical alignment with education and training to promote recovery competencies, and increased positive change and outcomes for consumers seeking or in need of recovery-oriented care. Ethically, counseling competencies outline the need to of evidence-based interventions and practice within ones' competencies; however, there are no core educational or training requirements in recovery for counselors.

Chapter 2 includes the literature and search strategies for this study. Additionally, a review of the theoretical foundation used in this study and the rationale to why the conceptual frame work of the recovery model was chosen. In Chapter 3, information about the research design and rationale, methodology, population, data analysis plan, and ethic procedure are discussed. Chapter 4 will include the results of the study and the statistical evidence that lead to the conclusions of the study. Chapter 5 discusses the interpretations of the finding, limitation of the study, recommendations for future research, and the implications of positive social change. 
Chapter 2: Literature Review

\section{Introduction}

Each year, millions of Americans 18 years of age and older experience some form of mental illness (Price et al., 2016; Substance Abuse and Mental Health Services Administration [SAMHSA], 2014). A portion of these adults experience SMI. The Diagnostic and Statistical Manual of Mental Disorders Fifth Edition (DSM-5) defines serious mental illness as a mental or emotional disorder (excluding developments and substance disorders); symptoms are experienced within the last 12 months and cause significant impairment to daily life. Those with SMI have higher rates for morbidity, mortality, isolation, stigma, and difficulties with illness management (Chronister et al., 2013; Sickels et al., 2014).

Historically, society viewed mental illness as a chronic and debilitating disease (Carpenter, 2002). Multiple studies in the 1970s and 1980s found that most individuals with mental illness could recover; leading full and active lives (Harding, Brooks, Asgikga, Strauss, \& Breier, 1986; Tsuang, Woolson, \& Fleming, 1979). Throughout the 1980s and early 1990s consumers and mental health professionals continued to give a voice to psychiatric rehabilitation and challenged the mental health system to adopt a recovery vision (Peebles et al., 2009). The recovery paradigm is the directed approach of mental health services within the United States after The New Freedom Commission on Mental Health published a report in 2003 that recognized the recovery paradigm as best practice in the delivery of mental health services (NFC, 2003; Ostrow \& Adams, 2012;

The President's New Freedom Commission on Mental Health, 2013). The recovery 
paradigm challenges professionals to join in partnership with consumers and their families to create a culture of recovery and empowerment, and to act as social change agents creating new opportunities for consumers on all platforms.

The literature on mental health recovery contains information on the knowledge and attitudes of mental health professionals including social workers (Carpenter ,2002; Clearly \& Dowling, 2009; Scheyett et al., 2009), psychiatrists (Peebles et al.,2009; Razzano et al., 2010; Stratford, Brophy, \& Castle,2012), and psychologists (Clearly\& Dowling, 2009; Peebles et al.,2009; Reddy, Spauldin, Jansen, Menditto, \& Pickett, 2010) but contains little information about counselors. There is a continued discussion about how mental health professionals can support consumer recovery, as mental health professionals can have positive or negative effects on consumer recovery (Berry \& Greenwood, 2015; Wilrycx, et al., 2015).

The purpose of this correlational quantitative study was to understand the relationship between counselors' knowledge and attitudes of the recovery paradigm. Achieving recovery is rooted in recovery-oriented care and services between all stakeholders (Ostrow \& Adams, 2012). Counselors, like social workers, psychiatrists, and psychologists, are vital stakeholders of the recovery paradigm.

In this chapter, I include a review of the literature, research strategies I plan to use to gather literature, key terms, databases, and theoretical foundation. Furthermore, I discuss my research outcomes and summarize major themes within the literature. I conclude by describing how my study will fill a gap within the literature and extend the knowledge of counselors. 


\section{The Wellness Paradigm}

Counselors subscribe to the wellness paradigm, a holistic paradigm that offers a philosophical base for counselors. The wellness paradigm offers counselors a unique approach to the treatment of mental health concerns. (Myers, 1992; Myers \& Sweeney, 2008; Roscoe, 2009). Counseling is rooted in human development across the lifespan, and originally focused on vocational development (Myers, 1992). The American Counseling Association (ACA), formerly the American Association of Counseling and Development (AACD), adopted a wellness approach as counseling professionals recognized the principles of wellness and development shared a unique role to the field of mental health (Myers, 1992).

Wellness and recovery are distinct yet interrelated concepts that have gained an increasing amount of attention and research as they apply to consumers and community mental health providers (Sterling, von Esenwein, Ticker, Fricks, \& Dress, 2010). Despite similarities, each concept is complex and defined differently by the various stakeholder groups (Sterling et al., 2010). Therefore, it is necessary to study counselors' knowledge and attitudes of the recovery paradigm to fill the gap in the existing literature.

\section{Literature Search Strategy}

To provide a thorough background on the topic of this study, I used the Walden University library to identify published peer reviewed literature. I also included a variety of online databases including, PsychINFO, Academic Search Complete, Google Scholar, and ProQuest. I used the search terms recovery, wellness, community mental health, serious mental illness, mental health recovery, consumer recovery, recovery knowledge 
inventory, wellness counseling, self-determination theory, stigma, recovery-orient training, consumer stigma, recovery paradigm, psychiatric rehabilitation, mental health stigma, and consumer movement. The literature includes published works within the last 10 years to establish the relevance of the topic. I used revised resources to include published documents within the last 5 years.

\section{Theoretical Foundation}

Both the working alliance and recovery strategies that mental health professionals utilize when working with consumers are associated with the positive and/or negative outcomes of consumer recovery (Berry \& Greenwood, 2015; Moran et al., 2014; Wilrycx, et al., 2015). The literature suggests that professional attitudes toward recovery greatly influence recovery outcomes (Kidd, Kenny, \& McKinstry, 2015; Stanhope et al., 2015). The recovery model supports collaboration, a working partnership, and consumer choice (Kidd, Kenny, \& McKinstry, 2015). The principles of the recovery model include self-direction, individualization, empowerment, holism, nonlinearity, use of strengths, peer-support, respect, responsibility and hope (SAMHSA, 2017). The recovery model promotes the idea that with hope, meaning, and purpose in life, people with serious mental illness can and do recover (Farkas, Anthony, \& Cohen, 1989; Farkas \& Anthony, 2010; SAMHSA, 2014). A consumer needs to create a sense of self aside from their mental illness, develop self-agency, find hope and support through professional and personal relationships, and improve their role functions through activities such as employment, education, parenthood, etc. (Mancini, 2008). The Wheel of Wellness has five principles which consist of spirituality, self-direction, work and leisure, friendship, 
and love (Myers, et al., 2000). Both the wellness paradigm and the recovery paradigm are health-centered rather than disease-centered and emphasize the role of the consumer in obtaining health and well-being, the two paradigms remain distinct from one another (Sterling, von Esenwein, Ticker, Fricks, \& Dress, 2010). While research suggests that the recovery model and wellness model have similar principles, research does not include counselors' knowledge and attitudes toward consumer recovery (Sterling et al., 2010). Therefore, it was necessary to view this study through a recovery lens to further understand the relationship between the recovery model and the wellness model, and what it means for the working alliance and implementation of recovery strategies.

\section{Serious Mental Illness}

One in every five or 43.6 million adults in the United States experience mental illness each year (National Alliance on Mental Illness [NAMI], 2016). Approximately $4 \%$ of those who experience mental illness have a SM. SMI is a mental disorder that results in a high degree, or serious impairment of daily functioning in more or more life activity (Han et al., 2015).

\section{Individual Impact}

The impact SMI has on an individual's thoughts, feelings, and behaviors can cause chronic stress, an inability to maintain employment, and deterioration of social functioning (Price et al., 2016). Morbidity and mortality are higher in those who have SMI, as individuals struggle with isolation, stigma, and difficulties with illness management (Chronister et al., 2013; Sickels et al.,2014). The estimated mortality gap for individuals with SMI such as bipolar disorder and schizophrenia is 2.22 times higher than 
the general population (Price et al., 2016; Woodhead, Ashworth, Schofield, \& Henderson, 2014). Furthermore, approximately $15 \%$ of all deaths in the United States involve an individual with mental illness (Price et al., 2016; Woodhead, et al., 2014). Many of these deaths are a result of comorbid physical illnesses such as heart disease, cancer, and stroke (Price et al., 2016; Woodhead, et al., 2014).

For many individuals who have SMI, their illness impairs the ability to maintain employment (Harper et al., 2015). As a result, many of these individuals rely on their family or public assistance to meet basic needs. These outcomes place individuals in poverty. Research on poverty has shown that living in poverty is associated with impaired cognitive functioning, lowered self-control, poor decision making (poor spending habits, impulsive behaviors, and financial victimization (Chronister et al., 2013; Harper et al., 2015, Price et al., 2014).

Similar to employment and economic disadvantages, stigma also has serious and devastating effects on the lives of individuals with SMI (Chronister et al., 2013; Corrigan, Druss, \& Perlick, 2014). Individuals with SMI experience stigma through society and individual internalization. Additionally, these individuals are labeled, discriminated against, and viewed as dangerous or erratic (Corrigan et al., 2014). Such social perceptions are especially dangerous for this population, as research continuously shows that stigma is associated with lower quality of life, social isolation, inadequate heath care, fewer jobs, and lowered self-esteem (Chronister et al., 2013). 


\section{Societal Impact}

Disability due to SMI has a significant financial impact on the U.S. Social Security Administration. In 2012, the Social Security Administration spent an estimated $\$ 467$ billion on benefits and premature morbidity (Price et al., 2014). In addition to the financial impact that SMIs have on the U.S. Social Security Administration, inpatient hospitalizations due to SMIs cost the United States Health System 6.6 billion dollars a year (Mansuri et al., 2016). After an initial hospitalization, individuals with a SMI, such as schizophrenia, have an estimated $80 \%$ chance of having a reoccurrence of psychosis within the first 5 years after their initial episode (Chi et al., 2016).

\section{Mental Illness Reform in the United States}

Historically, mental health professionals viewed mental illness as a chronic and debilitating disease (Carpenter, 2002; Glynn, 2014). The DSM published in 1952 described schizophrenia as a disease of progressive deterioration (Carpenter, 2002). However, mental health treatment perspectives began to shift in the 1950s and 1960s when individuals with SMI were deinstitutionalized (Cohen, Abraham, Burk, Stein \& 2012; Glynn, 2014). The deinstitutionalization of people with SMI coincided with the Community Mental Health Centers Act that President Kennedy signed in 1963 (Feldman, 2013; Murphy \& Riggs, 2014). This act established community-based treatment for individuals who were previously institutionalized due to mental illness and marked the beginning of vast changes for all mental health stakeholders (Feldman, 2013; Murphy \& Riggs, 2014). 
Indeed, the 1960s through the 1980s marked dramatic changes in mental health treatment in the United States (Cohen et al., 2012). During this time, activists, which included previously institutionalized patients, current patients, and family members, expressed their right to advocacy and self-determination (Cohen et al., 2012).

Specifically, consumers exuded their rights to remove complete control from psychiatry. Individuals with SMI began to identify themselves as consumers instead of patients (McLaughlin, 2009). This movement, known as the consumer or survivor movement, occurred simultaneously with the publication of new research about mental illness and recovery became influential in the development of the mental health recovery model (Peebles et al., 2009; Glynn, 2014). Such foundational research included studies by Harding, Brooks, Asgikga, Strauss, and Breier (1986) and Tsuang, Woolson, and Fleming (1979), who found that most individuals with mental illness could recover, leading full and active lives. Under this new model, according to Moran and RussoNetzer (2016), recovery is viewed as follows:

a deeply personal, unique process of changing one's attitudes, values, feelings, goals, skills and/or roles. It is a way of living a satisfying, hopeful, and contributing life even with limitations caused by the illness. Recovery involves the development of new meaning and purpose in one's life as one grows beyond the catastrophic effects of mental illness. (p. 273)

Consequently, community and peer supports are central to the recovery process. The creation of Alcoholics Anonymous, a consumer-based service, paved the way for the development of a similar mental health services known as psychiatric rehabilitation 
(Peebles et al., 2009). Psychiatric rehabilitation is a specialized field that promotes recovery, well-being, and community functioning (Roncone, Ussorio, Salza, \& Casacchia, 2016). In psychiatric rehabilitation, the consumer is central, as consumers set personal and obtainable goals through the integration of multidisciplinary supports (Roncone et al., 2016). Throughout the 1980s and early 1990s, consumers and mental health professionals continued to give a voice to psychiatric rehabilitation and challenged the mental health system to adopt a recovery vision (Peebles et al., 2009).

The recovery paradigm is the directed approach of mental health services within the United States (Ostrow \& Adams, 2012; The President's New Freedom Commission on Mental Health, 2013). The national acceptance of the recovery paradigm compels all mental health professionals to reevaluate and redefine their professional roles and identity as they apply to the consumer (Barton, 1998). Additionally, the recovery paradigm challenges professionals to join in partnership with consumers and their families to not only create a culture of recovery and empowerment, but also act as social change agents creating new opportunities for consumers on all platforms (Barton, 1998). One of the two central recommendations of the New Freedom Commission were that all services are designed to meet the needs of the consumer (Cohen et al., 2012). In other words, services are designed in such a way to incorporate consumer choice, and consumers should find services to be meaningful. Secondly, the design of all services should be to facilitate recovery (Cohen et al., 2012) through improving a consumer's resilience and independence in the community. 
Today, mental health recovery is a personal day-to-day lived experience (Cohen et al., 2012). Further, mental health recovery, as discussed in The New Freedom Commission's Report, shapes Federal and State policy, as recovery-oriented care is a standard of practice that has transformed the mental health system (Cohen et al., 2012). To continue to implement effective and efficient programing and policy that focuses on consumer recovery, it is important for all stakeholders to understand how a consumer recovers, programs and policies is monitored, and resources are used efficiently (OlmosGallo \& de Roche, 2010)

\section{Recovery Outcomes}

The implementation of consumer recovery seen throughout various professions and countries including Canada, Australia, and the United Kingdom (Hungerford, C., Dowling, M., \& Doyle, 2015). The literature contains research not only on consumer recovery in these countries, but the knowledge and attitudes of mental health professionals. Within the United States, the RKI is a commonly used inventory that measures professionals' knowledge and attitudes in terms of role and responsivity in recovery, nonlinearity of the recovery process, the role of self and peers in recovery, and expectation about recovery (Bedregal et al., 2006). Studies that include doctors (Peebles et al.,2009; Razzano et al., 2010; Stratford, Brophy, \& Castle,2012), social workers (Carpenter ,2002; Clearly \& Dowling, 2009; Scheyettet al., 2009), and psychologists (Clearly\& Dowling, 2009; Peebles et al.,2009; Reddyet al., 2010), indicate limited adoption and knowledge of recovery principles (Clearly \& Dowling, 2009). 
The method of this study, like the previous studies by Bedregal et al. (2006) and Clearly and Dowling (2009), applies quantitative research to survey counselors' knowledge and attitudes of the recovery paradigm using the recovery knowledge inventory. The RKI is a 20-item instrument that measures counselor's knowledge and attitudes of the recovery paradigm through four subscales (roles and responsibilities in recovery, nonlinearity of recovery, self-definition and peers in recovery, expectations regarding recovery). The questions in each scale follow a 5-point Likert response format ranging from 1 (strongly disagree) to 5 (strongly agree) (Bedregal et al., 2006). Additionally, a demographic questionnaire gathered information on the independent variables of gender, years of experience, licensure status, and practice setting. Previous research that uses the RKI to measure mental health professional knowledge and attitudes of the recovery paradigm include these variables. (Cleary \& Dowling, 2009; Crowe et al.,2013; Gaffey, K., Evans, D., \& Walsh, 2016; Meehan \& Glover, 2009; Peebles at al., 2009; Salgado, Deane, Crowe, \& Oades, 2010)

There is an absence of literature that contains research on counselors' knowledge and attitudes of recovery. However, a study completed by Crowe et al. (2013) that includes counselors as participants, indicated a significant improvement in counselor's knowledge, attitudes, and confidence/competence post internship. The improvement in counselor's knowledge and attitudes of consumer recovery after training and education reflects common outcomes among other mental health professionals (Cavelti, Homan, \& Vauth, 2016; Green et al., 2008; Wilrycx, et al., 2015). Additionally, the knowledge and support of consumer recovery is correlated with higher levels of consumer engagement, 
satisfaction, symptoms reduction, and greater attained recovery and quality of life (Green et al., 2008). The absence of studies like Crowe et al. (2013) is a gap in the literature that I address through this study.

\section{The Wellness Paradigm}

Unlike other mental health professionals who subscribe to the recovery paradigm, counselors subscribe to the wellness paradigm (Myers, 1992; Myers \& Sweeney, 2008; Roscoe, 2009). Today's counseling began as vocational guidance (Smith, 2012). Social reform at the turn of the 20th century and the Reconstruction Era following the Civil War focused on humanitarian concerns, educational and vocational guidance, and societal welfare (Smith, 2012). Pioneers in the field of vocational guidance, such as Salmon Richards and Frank Parsons, believed that individual development would improve with direction and guidance of vocational education (Gysbers \& Henderson, 2001).

The mental health professional saw the first published Diagnostic and Statistical Manual of Mental Health (DSM) in 1952. With the addition of the first DSM and new research, the field of counseling transformed. Guidance professionals became concerned with human development across the lifespan, originally regarding vocational development (Myers, 1992). The American Personnel and Guidance Association (APGA) and the American Psychological Association (APA) Counseling Psychology

division formed as a result of new information and approaches during the 1950s (Smith, 2012). The APGA united mental health counselors and vocational counselors.

Later, in the 1960s, the Community Mental Health Centers Act moved mental health treatment from state hospitals to the communities where consumers lived (Smith, 
2012). This movement added over 2,000 community mental health centers in the United States (Grob, 2014). The Vocational Rehabilitation Act (1973) required counseling services for those with disabilities, including mental illness, and specific training for professionals working in the field (Gysbers \& Henderson, 2001). Communities and mental health professional experienced an expansion of the Community Mental Health Act in 1975. In response to the expansion, counselor education programs focused on preparing students to work in community mental health settings (Smith, 2012). The need for credentialing was recognized, and in 1976 Virginia became the first state to license counselors.

Wellness, as it is known today, is rooted in psychology (Schueller, 2009). The promotion of wellness as a means of improving human life was recognized as early as the turn of the 20th century. Humanistic psychologists such as Maslow and Rogers reflected on this perspective and argued that psychologists needed to help people achieve a full potential (Schuller, 2009). Carl Rogers was the first to use the term "client" as the humanistic approach moved away from viewing the psychologist as the specialist and focused on the congruence of the counseling relationship (Cooper \& McLeod, 2011). Additionally, a humanistic approach requires the client to take an active role in his or her treatment.

It was the American Counseling Association (ACA), formerly the AACF, that adopted a wellness approach as counseling professionals recognized the principles of wellness and development shared and the unique contribution the ACA could make to the field of mental health (Myers, 1992). There are two current models of wellness that 
counselors use: the wheel of wellness and the indivisible self (Hattie, Myers, \& Sweeney, 2004; Myers, Sweeney, \& Witmer, 2000; Myers, \& Sweeney, 2004). The wheel of wellness model was first introduced in 1991 and was the first theoretical model in wellness based counseling (Hattie et al., 2004; Myers et al., 2000; Sweeney, 2004). The model incorporates researched based characteristics of healthy individuals and individual psychology. The Wheel of Wellness has five principles which consist of spirituality, selfdirection, work and leisure, friendship, and love (Myers, et al., 2000). The principles are measured using the wellness evaluation of lifestyle (WEL), a 123-item questionnaire. Similarly, the indivisible self includes five factors that create the self; however, this model views wellness across the lifespan. These factors include the creative self, the coping self, the social self, the essential self, and the physical self (Myers \& Sweeney, 2004). The 73-itemed five-factor wellness inventory (5F-WEL) measures the principles of the indivisible self model.

\section{Integration of Wellness and recovery paradigms}

Wellness and recovery are distinct yet interrelated concepts that have gained an increasing amount of attention and research as they apply to consumers and community mental health providers (Sterling, von Esenwein, Ticker, Fricks, \& Dress, 2010).

Wellness originates from alternative medicine, while recovery comes from the consumer movement (Sterling et at al., 2010). Both paradigms focus on health versus disease and emphasize the role of the consumer in the management of their health (Sterling et al., 2010). Despite similarities, each concept is complex and defined differently by the various stakeholder groups (Sterling et al., 2010). However, despite distinct and disparate 
definitions, both wellness and recovery are connected by the shared dimensions of holism, patient-centeredness, and nonlinearity (Sterling et al., 2010). In other words, both wellness and recovery are health-centered rather than disease centered, emphasizing the role of the consumer rather than the professional as the determinant of choices surrounding health and well-being (Sterling et al., 2010). Applying the dimensions of holism, patient-centeredness, and nonlinearity, as well as other recovery principles that wellness and recovery do not share, is ethically necessary to support consumers under the recovery paradigm. Counselors hold ethics that speak to following best practices and obtaining knowledge to practice within specialized areas.

\section{ACA Code of Ethics}

Counselors, like other mental health professionals, subscribe to a code of ethics which outlines the mission and values to which they are to follow. The American Counseling Association (ACA) code of ethics, as it applies to counselors' knowledge and attitudes toward the professional relationship and clinical interventions, suggests that counselors complete continuing education to practice current scientific and professional skills that maintain counseling competence and that align with best practices for working with diverse populations (ACA, 2014). Additionally, the code of ethics outlines that counselors only accept positions for which they have training and experience in, and take steps to improve their qualifications and effectiveness as necessary (ACA, 2014).

Upholding the ACA code of ethics provides a map for counselors to uphold practices that promote the best possible outcomes for consumers. Mental health professionals can affect their clients in both positive and negative ways (Wilrycx, Croon, Van den Broek, \& van 
Nieuwenhuizen, 2015). The recovery paradigm is the directed treatment paradigm within the United States. According to the recovery movement's principles, the professional relationship with consumers must consist of empathy, presence, disclosure equality and reciprocity (Wilrycx et al., 2015). All of these principles require mental health professionals, including counselors, to have a different attitude toward recovery than other mental healthcare professionals (Wilrycx et al., 2015). Therefore, the literature and counseling ethics suggest the importance of counselor training. Previous research that includes social workers, nurses, psychiatrists, and psychologists showed a change in attitudes and knowledge of recovery principles after recovery-oriented training. This study proposes to find out what counselors existing knowledge and attitude are so that ethics are upheld, and counselors are practicing evidenced-based interventions that support consumer recovery.

\section{Summary}

The literature review in chapter two discusses the impact of serious mental illness on the consumer and society, the transformation of mental health care over time, and the similarities and differences between the recovery paradigm and the wellness paradigm. Researchers described the positive and negative impacts that mental health professionals can have on consumers regarding their knowledge and attitudes toward recovery (Cavelti, Homan, \& Vauth, 2016; Green et al., 2008; Wilrycx, et al., 2015). Wellness and recovery are distinct yet interrelated concepts (Sterling, von Esenwein, Ticker, Fricks, \& Dress, 2010). Counselors are trained to follow the wellness paradigm despite recovery paradigm being the directed approach to mental health treatment in the United States (Hattie, 
Myers, \& Sweeney, 2004; Myers, Sweeney, \& Witmer, 2000; Myers, \& Sweeney, 2004). The ACA code of ethics outlines the need for counselors to be competent in best practices. The current study fills the gap in the literature by investigating counselors' knowledge and attitudes of the recovery paradigm. Chapter 3 proposes the use of quantitative research to understand counselor's knowledge and attitudes of the recovery paradigm. This chapter identifies the sample population, sampling method, data collection method, and data analysis of the current study. 
Chapter 3: Research Method

\section{Introduction}

The purpose of this quantitative study was to understand what factors contribute to counselors' knowledge and attitudes of the recovery paradigm through survey research methodology (Creswell, 2009; Fields, 2013). In this chapter, I include a description of the my research design and the rationale for why I selected this research design. I also include the discussion of the methodology including population, sampling, data collection, instrumentation, data analysis, limitations, delimitations, assumptions, and ethical considerations. I conclude this chapter with a summary of my research methods.

\section{Research Design and Rationale}

In this quantitative study, I used survey research methodology to understand what factors contribute to counselors' knowledge and attitudes of the recovery paradigm (Creswell, 2009; Franfort-Nachmias \& Nachmias, 2008). In my online survey, I used the Recovery Knowledge Inventory (RKI, Bedregal, O’Connell \& Davidson, 2006) and a Demographics Information Questionnaire (DIQ). I used the RKI (Bedregal, O’Connell \& Davidson, 2006) to measure counselors' knowledge and attitudes of recovery practices. I created the DIQ to collect participant demographic data including gender, years of experience, licensure status, and practice setting (community outpatient [a communitybased behavioral health program that is financially supported by county monies], private practice [owned or contracted by a counselor], hospital, residential setting, or other). According to Bedregal e al. (2006) the dependent variables consisted of the four RKI 
subscales which include roles and responsibilities, nonlinearity of recovery, roles and self-definition of peers in recovery, and expectation regarding recovery.

I used an online survey to collect participant data. Online survey programs such as Survey Monkey support the preparation of quantitative data as it organizes participants' responses into a compatible format for data analysis software (Creswell, 2009). Advantages on online surveys include the ability to collect data electronically with quick results, and the ability to obtain data from large numbers of the population (Creswell, 2009).

I entered a demographic questionnaire and the RKI into the Survey Monkey program (Appendix B). The research design and data collection method were appropriate for my study as the method allows researchers to answer questions through specialized surveys that participants will complete (I rejected other research designs as they were not appropriate for this study. For example, Creswell (2009) and Frankfort-Nachmias \& Nachmias (2008) suggest the use of a qualitative design to explore a phenomenon; however, this was not my goal for this study. Researchers use a quantitative study to examine research questions and hypotheses with statistical outcomes and associations between variables (Creswell,2009). The goal of this study was to explore the demographics that contribute to counselors' knowledge of and attitudes toward the recovery paradigm as measured through a demographics questionnaire and the four subscales of the RKI. I rejected other research designs as they could not be used to examine the relationship between the study variables. Therefore, I found a cross-sectional design is the most appropriate for this study. 


\section{Methodology}

In the following sections, I present them information concerning the population, sampling procedures, the method of data collection, the instrumentation, and the proposed data analysis process. Finally, I conclude this chapter with the discussion of the ethical procedure.

\section{Population}

The target population in this study was counselors, both licensed and nonlicensed. Studying licensed and nonlicensed counselors was beneficial for the study because both groups may practice within a variety of community setting. The ACA is the world's largest professional organization that dedicates itself to the professional growth of the counseling profession (ACA, 2017). The ACA defines counseling as, "a professional relationship that empowers diverse individuals, families, and groups to accomplish mental health, wellness, education, and career goals" (ACA, 2017, 1). According to The U.S. Bureau of Labor and Statistics Occupational Handbook of 2016, there are 139,830 counselors nationwide (U.S. Bureau of Labor Statistics, 2017). The handbook groups counseling specialties in this number; however, each specialization requires a minimum of a master's degree.

\section{Sampling and Sampling Procedure}

I restricted participation to counselors who participate in the ACA, Counselor Educator and Supervisor Network Listserv (CESNET-L), or counseling network groups through Facebook (Professional Mental Health Counselors, Social Workers, \& Psychologists, Action Research Network, Mental Health Counselors Networking Group, 
Online Counseling Referral Network, Counselor/Therapist Networking/Consultation Group), hold a masters or doctoral degree in counseling, and practice within a community setting. A community setting included community outpatient (county funded), private practice (owned or contracted), hospital, residential facility, or other. Exclusion criteria include mental health practitioners who do not identify themselves as counselors such as social workers, psychologists, case workers, and marriage and family therapists as their expertise differs from counselors and would not adequately represent the study population. These restrictions created barriers to a representative sample, for example, counselors who chose not to hold membership in the ACA, CESNET- L, professional networking groups though Facebook (Professional Mental Health Counselors, Social Workers, \& Psychologists, Action Research Network, Mental Health Counselors Networking Group, Online Counseling Referral Network, Counselor/Therapist Networking/Consultation Group) would not be represented; however, the sample that was obtained from these organizations provides representation of the demographic variables to generalize this study.

Sample sizes from previous research using the RKI vary. Initial testing of the RKI in the state of Connecticut included 169 staff from nine different agencies that provided both mental health and addictions services (Bedregal et al., 2006). The purpose of the author's testing was to describe the RKI and its preliminary psychometric properties and to provide an example of its use in assessing the training needs of staff who were expected to deliver recovery-oriented services (Bedregal et al., 2006). Researchers since then have had similar purposes with varying populations and sample sizes. Clearly and 
Drowling's (2009) study included 153 health care professionals that consisted of nurses, doctors, social workers, occupational therapists, and psychologists. Peebles et al. (2009) included 39 participants from the Medical College of Georgia (MCG). A more recent study by Crowe et al. (2013) included 54 participants who were interns of a co-occurring program.

In research, it is important to establish the statistical power or the probability to avoid making a type II error (Field, 2013). While there are statistical equations that are beneficial in determining statistical power, for this study I used the G*Power software program to complete the statistical power based on the statistical test required for analyzing the research hypothesis. For this study, I chose a medium effect size of .0625 , as medium effect size is most commonly used in the social sciences according to Field (2013). The statistical test was set for MANOVA: Global Effects. Additionally, the $\mathrm{x}$ error will be set to .05 and the statistical power to .95 , both commonly accepted in the social sciences (Fields, 2013). The number of tested groups is three, and total number of response variables is four. I determined that the required sample size was $N=186$ participants. However, the sample size is only a minimum number of participants. To counter the issue of generalizability, Field (2013) suggests aiming for a larger sample size of 225 to allow for response errors or incomplete participation.

I used convenience sampling for this study. Frankfort-Nachmias \& Nachmias (2008) discuss the ability to select sample units conveniently available from the email lists, and the probability of qualified participants on these lists when using convince sampling. Convenience sampling compliments my use of survey research as both 
convenience sampling and survey research allowed me to reduce my time to collect data, reduce cost, and allow me to have readily accessible participants from my population outlined for my A potential limitation of convenience sampling is that conclusions I drew from data collected from my sample may not represent the whole population Although using a random sample could have eliminate the limitation of population representation, according to Franfort-Nachmias and Nachmias (2008), there was no way for this study to access all counselors who meet inclusion criteria, creating its own limitation of population representation Additionally, I decided that random sampling would not be appropriate to this study as my sample consisted of a naturally formed group, which contradicts what a random sample is according to Creswell (2009) and FranfortNachmias and Nachmias (2008). To overcome the limits of generalizability of a convenience sample, this study included a larger sample size of 225 participants (Franfort-Nachmias \& Nachmias, 2008).

\section{Procedures for Recruitment, Participation, and Data Collection}

This study began once I gain approval from Walden University’s Institutional Review Board (IRB) for Ethical Standards in Research. I used the American Counseling Association's (ACA) Connect Community Calls for Study Participants, the Counselor Educator and Supervisor Network Listserv (CESNET-L) listserv, and identified counseling network groups through Facebook (Professional Mental Health Counselors, Social Workers, \& Psychologists, Action Research Network, Mental Health Counselors Networking Group, Online Counseling Referral Network, Counselor/Therapist Networking/Consultation Group). The Connect Community is a forum for counselors, 
counselor educators, and counselor education students (ACA, 2017). The ACA Connect Community requires that researchers post specific information about themselves, and that researchers follow the community forum's rules and etiquette (Appendix D). In concordance with the ACA code of ethics (ACA, 2014), I provided an entry page that will offer information about the study including an overview and background that will include the procedure, voluntary consent to participate, risks and benefits of the participant's participation in the study, information on compensation, confidentiality, and contact information (Appendix D).

The Counselor Educator and Supervisor Network Listserv (CESNET-L) listserv is a forum for counselors, educators, and supervisor (ACA, 2017). Similarly, to the ACA Connect Community, CESNET-L requires that researchers post specific information about themselves, and that researchers follow the community forum's rules and etiquette (Appendix F). In concordance with the ACA code of ethics (ACA, 2014), I also provided an entry page for CESNET-L that offered information about the study including an overview and background that will include the procedure, voluntary consent to participate, risks and benefits of the participant's participation in the study, information on compensation, confidentiality, and contact information (Appendix E).

The identified counseling networking groups (Professional Mental Health Counselors, Social Workers, \& Psychologists, Action Research Network, Mental Health Counselors Networking Group, Online Counseling Referral Network, Counselor/Therapist Networking/Consultation Group) required permissions to join (Appendix F) and post my advertisement. Again, similar to the ACA Connect Community and CESNET-L, 
counseling networking groups requires that participants post specific information about themselves, and that researchers follow the community forum's rules and etiquette (Appendix F). In concordance with the ACA code of ethics (ACA, 2014), I also provided an entry page for counseling networking groups that offered information about the study including an overview and background that included the procedure, voluntary consent to participate, risks and benefits of the participant's participation in the study, information on compensation, confidentiality, and contact information (Appendix F).

Once participants reviewed the noted entry/introductory information, participants began the survey that included the Recovery Knowledge Inventory (See Appendix B) and a Demographics Information Questionnaire (See Appendix A). Once participants completed the surveys, the participants received a debriefing statement that thanked them for sharing information needed for the study which included a copy of my contact information, reiterate the voluntary nature of the study, review informed consent, and shared counseling resources. I collected data at one time without follow-up contact. If participants exited the study without completing the survey, participants had the opportunity to access the survey link again to complete the survey from the beginning. After I obtained the target sample size, I downloaded the survey data to SPSS software on a password protected computer for analysis.

\section{Instrumentation and Operationalization of Constructs}

Demographics Information Questionnaire (DIQ). I used a demographics questionnaire to obtain participants' gender classification, years of counseling related experiences, and professional setting (Appendix A). I chose the variables of gender, years 
of experience, and professional setting because of their significance in previous research of Cleary and Dowling (2009), Crowe et al. (2013), Gaffey, K., Evans, D., and Walsh (2016), Meehan and Glover (2009), Peebles at al. (2009), and Salgado, Deane, Crowe, and Oades (2010). Participants had the option of choosing the gender of male, female, trans, other, or not disclosing their gender. Participants provided a numerical response to the number of years of experience they had working as a master's level counselor postgraduation. The research of Gaffey et al. (2016) and Salgado et al. (2010) used years of experience as a demographics question in their research. The final demographics question asked participants to select their practice setting. Participants chose from community outpatient, private practice, hospital, residential, or specifying other. The research varied greatly in terms of setting. While some researchers focused on one primary setting such as a hospital or residential setting (Peebles et al., 2009), other researchers included practitioners from broad practice settings (Cleary \& Dowling, 2009).

Recovery Knowledge Inventory (RKI). I used RKI to measure participants’ knowledge and attitudes of recovery principles and practices. The RKI is a 20 -item instrument that uses a 5-point Likert response format ranging from 1 (strongly disagree) to 5 (strongly agree; Bedregal et al., 2006). Scoring is determined by obtaining the means for each dimension and then judging each factor's mean according to the Likert Scale. Mean scores of four and five equate to demonstrating strong recovery knowledge, a mean score of three equates to adequate recovery knowledge, and mean scores of two and one equate to poor recovery knowledge. 
To measure the psychometric properties of the RKI, the authors performed a principle component analysis (PCA) using 144 completed assessments (Bedregal et al., 2006). The analysis generated five components with eigenvalues greater than the 1.0. The criteria of this assessment forced the authors to load scale items into four components. The eigenvalues of the four retained components were 4.96, 2.43, 1.43, and 1.21. The four-factor structure was labeled as Roles and Responsibilities in Recovery which includes seven items pertaining to risk taking, decision-making, and self-determination $(2,6,7,9,10,11$, and 18); Non-Linearity of Recovery which includes six items pertaining to symptom management, integration of illness into one's life, and recovery process (4, 14, 15, 16, 17, and 19); Self-Definition and Peers in Recovery which includes five items pertaining to involvement in relevant activities, support system, and development of a healthy identity (1, 3, 8, 12, and 20); and Expectations Regarding Recovery which includes 2 items pertaining to hope and extent to which one is capable of engaging in the recovery process (5 and 13) (Bedregal et al., 2006).

These four dimensions accounts for $50 \%$ of the variance and is broken in the following ways: roles and responsibilities in recovery is composed of seven items (e.g., risk-taking, decision-making, and roles and responsibilities of individuals and care providers) explains $17 \%$ of the variance. Non-linearity of the recovery process consists of six items (e.g., the role of illness and symptoms management and the non-linear nature of recovery) explains $13 \%$ of the variance. The roles of self-definition and peers in recovery is composed of five items (e.g., activities that define a client's identity, life, and goes beyond the idea that clients are simply "mental patients") accounts for $12 \%$ of the 
variance. The last component is expectations regarding recovery which includes two items (e.g., not everyone is capable of actively participating in the recovery process) explains $8 \%$ of the variance. Cronbach's alpha is used to test the reliability or internal consistency of test items. Reliability Cronbach's alpha of .70 or higher is considers acceptable in most social sciences (Creswell, 2009). The Cronbach's alphas of the four components of the RKI were .81, .70, .63, and .47, respectively (Bedregal et al., 2006). Bedregal and colleagues acknowledged the RKI's weak psychometric properties and recognized the need for further research into the measure's development. The developers also recognize that they still need to complete appropriate validation studies (Bedregal et al., 2006). Despite the need for further research by the developers of the RKI, previous researchers have found that the RKI is suitable for research on recovery-oriented competencies and the recovery-promoting relationship for professionals working with people with serious mental illness (Cleary \& Dowling, 2009; Gaffey, et al., 2016;

Wilrycx, et al., 2015)

\section{Data Analysis Plan}

Once the desired number of participants completed the survey on Survey Monkey, I downloaded results to a Microsoft Excel file to code and clean. According to Frankfort Nachmias and Nachmias (2008), coding is simply the organization of the data by unit of analysis. I coded the data by demographic variables (IV) and RKI variables (DV). Data cleaning is the process of reviewing the collected data to identify and address potential errors such as a missing or unrelated response (Frankfort Nachmias \& Nachmias, 2008). Further data screens checked for skewness and kurtosis (Field, 2013). Skewness and 
kurtosis can affect normal distribution. Positive skewness can indicate too many low scores in the distribution, whereas too many negative scores can indicate a buildup of high scores (Field, 2013). Positive kurtosis and indicate a pointed and heavy distribution, whereas negative kurtosis indicates a flat and light distribution (Field, 2013). Following statistical guidelines, the tolerance of +2 and -2 is acceptable for this study (Field, 2013). I conducted spot-checking as an initial means ensuring that my data is free from error. I compared the participant's responses from Survey Monkey with the SPSS file. I also eyeballed the results to confirm that I used the correct coding for each response. Next, I used is a logic check. The logic check included my review of participants' responses to verify that participants gave rational responses to the related question. I used the SPSS software to identify outliers and to assess distribution. An analysis of the descriptive statistics in SPSS identified outliners and distribution with plot and graph data representation (Fields, 2013). I removed score item outliners that contributed to incorrectly measured data, incorrectly entered data, and outliers that impact the assumptions of the test will be reviewed and noted in the results (Field, 2013; FrankfortNachmias and Nichmias, 2008). Given the categorical variables for gender, practice location, and licensure status, I used dummy variables (Field, 2013). Participants had the option of choosing the gender of male, female, trans, other, or not disclosing their gender. Male were coded as one, female coded as two, trans coded as three, other coded as four, and no disclosure as zero. For practice location, participants chose from community outpatient, private practice, hospital, residential, or specifying other. Community outpatient was coded as one, private practice coded as two, hospital coded as three, 
residential coded as four, and other coded as zero. Licensure status was codes as zero for nonlicensed and one for licensed. The dummy variable were then placed into the regression analysis for computation.

A concern when using a regression model is the phenomenon of multicollinearity (Field, 2013). Multicollinearity occurs when there are high correlations between two or more predictor variables. This phenomenon makes it difficult to assess the effect of the independent variables on the dependent variables. To address this concern, I used collinearity diagnostics through SPSS such as the variance inflation factor (VIF). VIF indicated whether a predictor variable has a strong relationship with another predictor variable (Field, 2013). I included years of experience, gender, professional setting, and licensure status as they offer statistical significance in relation to the dependent variables ( a) Roles and responsibilities in recovery, b) Non-linearity of the recovery process, c) The roles of self-definition and peers in recovery, and d) Expectations regarding recovery) in previous research (Cleary \& Dowling, 2009).

Once cleaned and coded, I calculated descriptive statistics (range, mean, frequency, percent, and standard deviation) to examine the data from the surveys. To test the hypothesis of this study, I employed the use of a multiple variable multiple regression. Multiple regression is an extension of linear regression (Fields,2013). Researchers use a multiple regression when they want to predict the value of a variable based on multiple other variables, or the value of Y( RKI subscales) for the given values of X1, X2, X2 ( gender, years of experience, and practice setting). I used SPSS to generate statistics for the study which will include post hoc testing (IBM Corporation, 
2015). The SPSS software provides researchers an opportunity to enter survey data which they can then analyze in a wide varied of statistical calculations which test hypotheses in quantitative research (Field,2013).

The proposed study addressed the following research question and hypotheses:

Research Question 1 (RQ1): Among professional counselors, does years of experience, gender, professional setting, and licensure status, as measured by a demographic questionnaire, correlate to professional counselors' (a) attitudes and level of knowledge of the recovery paradigm, (b) knowledge and attitudes of the roles and responsibilities in recovery, (c) understanding and attitudes toward the personal journey of the recovery process, (d) knowledge and attitudes of the roles of self-identity and peer support in recovery, and (e) knowledge and attitudes of the expectations regarding recovery as measured by the four subscale of the RKI.

H0 Is there a statistically significant relationship between counselors' years of experience, gender, professional setting, and licensure status as measured by a demographic survey and counselors' knowledge and attitudes of the roles and responsibilities in recovery as measured by the RKI

Ha There is no statistically significant relationship between a regression model including years of experience, gender, professional setting, and licensure status as measured by a demographic survey and counselors' knowledge and attitudes of the roles and responsibilities in recovery as measured by RKI.

H0 Is there a statistically significant relationship between a regression model including years of experience, gender, professional setting, and licensure status as 
measured by a demographic survey and counselors' understanding and attitudes towards the personal journey of the recovery process as measured by RKI.

Ha There is no statistically significant relationship between a regression model including years of experience, gender, professional setting, and licensure status as measured by a demographic survey and counselors' understanding and attitudes towards the personal journey of the recovery process as measured by RKI.

H0 Is there a statistically significant relationship between a regression model including years of experience, gender, professional setting, and licensure status as measured by a demographic survey and counselors' knowledge and attitudes of the roles of self-identity and peer support in recovery as measured by RKI.

Ha There is no statistically significant relationship between a regression model including years of experience, gender, professional setting, and licensure status as measured by a demographic survey and counselors' knowledge and attitudes of the roles of self-identity and peer support in recovery as measured by RKI.

H0 Is there a statistically significant relationship between a regression model including years of experience, gender, professional setting, and licensure status as measured by a demographic survey and counselors' knowledge and attitudes of the expectations regarding recovery as measured by RKI.

Ha There is no statistically significant relationship between a regression model including years of experience, gender, professional setting, and licensure status as measured by a demographic survey and counselors' knowledge and attitudes of the expectations regarding recovery as measured by RKI. 


\section{Threats to Validity}

Convenience sampling is a threat to my study. External validity is related to generalizability (Creswell, 2009). The threats to external validity as they apply to this study include: (a) the interaction of history and treatment, (b) the interaction of selection and treatment, and (c) the interaction of setting and treatment (Creswell, 2009). Generalizability of this study will be limited to ACA members that hold masters and doctorates in counseling, and that practice in community settings. Therefore, finding were not generalized to other populations.

Although it is important to discuss the threats to internal validity, I did not believe it was a concern at the time of the study. Threats to internal validity include: (a) history, (b) maturation, (c) statistical regression, (d) selection, (e) mortality, (f) instrumentation,

(g) testing, and (h) diffusion of treatment (Creswell, 2009). This study was completed one time without further interaction or lapse in time thus reducing the threats of: (a) history, (b) maturation, (c) mortality, and (d) testing. Surveys were completed on a voluntary basis, and all participants completed the same survey that used the same instruments and the same directions, therefore, reducing the threats of statistical regression and instrumentation (Creswell, 2009).

\section{Ethical Procedures}

I adhered to the ethical requirements of the ACA and by the Walden IRB (ACA, 2014; Walden University, 2017). In concordance with these requirements, I provided all participants with informed consent agreements before beginning the study. Informed consent included details about the purpose of the study, risk and benefits, the voluntary 
nature, limits confidentiality and privacy, and the contact information of the researcher and Walden University representative. As a requirement of the IRB, I attached a copy of my completion of the National Institute of Health Office of External Research Protecting Human Rights web-based training. This study was a survey design, which maintained the autonomy of participants through an online modality. Survey Monkey (2017) offers users an encrypted program that requires user authentication and password protection. The Survey Monkey program also allows researchers to export data in various formats that I downloaded and saved in a password-protected and encrypted SPSS file. After the completion of the study, I will store the data on a USB for five years and destroy it at the end of the five-year period. Participants were an adult population that held a masters or doctoral level education in counseling, a specialty that offered the experience required to respond to survey questions. The may have involved the risk of minor discomfort, similar to that which is experienced in daily life. I included the website for the NBCC for the purpose of counseling referrals. Study results are present with honesty and free from manipulation.

\section{Summary}

In chapter three I discuss, the study’s research design, sample, methodology, instrumentation, data analysis, and ethical considerations. I also explain and justified my sampling method and procedure. In chapter four, I explore the results of this study. I also summarize the results of the analysis and provide an account of the participants sampled in this study. 
Chapter 4: Results

\section{Introduction}

My purpose for this quantitative study was to understand factors that relate to counselors' knowledge of and attitudes toward the recovery paradigm using survey research methodology. I described the background of the study and provided a literature review in Chapters 1 and 2. In Chapter 3, I discussed the methodology of this study. To conduct this study, I tested the hypotheses informed by the literature review to understand the relationship between counselors' knowledge and attitudes of the recovery paradigm. The independent variables were gender, years of counseling related experiences, professional setting, and licensure status, and the dependent variables were RKI subscales. I followed the data collection procedures described in Chapter 3, including recruitment of the sample population, and data collection methods. In Chapter4, I review data collection process and provide the results of my analysis, including descriptive statistics and the statistical analyses.

\section{Data Collection}

I recruited participants for the study from one or more of the following electronic meeting sites: the ACA's listserv, the CESNET-L listserv, the Professional Mental Health Counselors Facebook Group, the Social Workers Facebook Group, the Psychologists Facebook Group, the Action Research Network Facebook Group, the Mental Health Counselors Networking Group on Facebook, the Online Counseling Referral Network Facebook Group, and the Counselor/Therapist Networking/Consultation Facebook Group. 
Participants of this study had all obtained a masters or doctoral degree in counseling and practiced within a community setting. I defined practice setting as a community outpatient (county funded), private practice (owned or contracted), hospital, residential facility, or other. I did not include any mental health practitioners who did not identify themselves as counselors, such as social workers, psychologists, case workers, and marriage and family therapists, in my sample as their expertise differentiates from counselors and would not adequately represent the study population. Although I recruited from online groups that may include professionals other than counselors, the invitation to participate specifically requested counselors. A participant who identified as another specialty on the DIQ was removed from the participant pool.

I used convenience sampling by posting an invitation to participate on the above identified counseling groups pages and boards. I obtained slightly more than half of the sample size over the course of 8 weeks. At 8 weeks, I requested IRB approval to expand my sampling frame to include five online counseling groups through Facebook. Within 3 weeks of expanding my search to include the additional five counseling groups, I obtained the sample size of 225 , a larger sample size then calculated through $\mathrm{G}^{*}$ Power, which allowed for response errors or incomplete participation.

\section{Data Cleaning and Coding}

Once I obtained the sample size of 225 , I downloaded the completed surveys to a Microsoft Excel file. I cleaned and coded responses following the data analysis plan which included screening for skewness and kurtosis, spot checking responses, logic checking, and assigning dummy variables. Upon cleaning and coding the data, I removed 
26 survey responses due to incomplete surveys, nonrational responses, or identified outliers, which resulted in 199 viable survey responses used to test the research questions. I uploaded the viable responses to SPSS for further analysis. The scoring directions of the RKI required the reverse scoring for some of the items (i.e., a score of 1 became a 5, a 2 became a 4 , a 3 remained the same, a 4 became a 2, and a 5 became a 1), which was completed through SPSS programing. Because gender, practice location, and licensure status are categorical in nature, I coded each variable with a dummy variable.

Following the guidelines for statistical assumptions, I tested for skewness and kurtosis. Skewness and kurtosis can affect normal distribution. Positive skewness can indicate too many low scores in the distribution, whereas too many negative scores can indicate a buildup of high scores (Field, 2013). Positive kurtosis can indicate a pointed and heavy distribution, whereas negative kurtosis indicates a flat and light distribution (Field, 2013). My analysis for skewness and kurtosis uncovered a leptokurtic kurtosis of 3.51 in the IV, "symptom reduction is an essential component of recovery." Leptokurtic kurtosis above 3.51 indicates extreme outliers. As noted above, outliers were removed during the data cleaning process. The results from my analysis for skewness and kurtosis indicated that that the subscales were within the range of $+2 /-2$ tolerance (Field, 2013) meaning scores had normal distribution.

A concern when using a regression model is the phenomenon of multicollinearity (Field, 2013). Multicollinearity occurs when there are high correlations between two or more predictor variables. This phenomenon makes it difficult to assess the effect of the independent variables on the dependent variables. To determine if multicollinearity 
existed, I used the variance inflation factor (VIF). I compared the results of the VIF to the Field's (2013) guidelines when assessing for multicollinearity. The outcomes of the VIF did not indicate multicollinearity in the predictor variables.

\section{Results}

I entered the collected data into the SPSS software to analyze the collected responses from the survey. Descriptive statistics, reliability estimates, and linear regression analyses provided insight into the relationships among race, ethnic identity awareness, and multicultural competence.

\section{Characteristics of the Study Participants}

Most of the counselors who responded to this survey reported having less than 10 years' experience. Forty-two and a half percent $(n=67)$ reported having between 1 to 5 years' experience. Thirty percent $(n=60)$ of participants reported having between 6 to 9 years' experience. Counselors with 10 to 30 years of experience made up $35 \%(n=69)$, while those with less than a year experience accounted for $1.5 \%(n=3)$. Although $35 \%$ of participants reported having 10 to 30 years of experience, participants with less than 10 years' experience created the majority of participants in this study.

I asked participants to identify their practice location with the options of choosing: community outpatient (county funded), private practice (owned or contracted), hospital, residential, or other. Participants who chose other were able to write in a response. Over $41 \%(n=83)$ of participants indicated they worked in private practice. Second to private practice was the community outpatient setting; over $30 \%(n=61)$ of participants identified this as their practice setting. More participants chose other than the 
hospital setting of $6.5 \%(n=12)$ and residential setting of $4 \%(n=8)$ combined. Seventeen percent $(n=34)$ of respondents chose other and wrote in their identified practice setting. Other included the educational setting, detention setting, homeless shelter, insurance/managed care setting, a non-profit organization, and government agency.

Of the total number of participants, $85 \%(n=169)$ identified themselves as licensed. The other 15\% (30) of participants identified as nonlicensed. Well over the majority of participants who participated in this study were licensed counselors.

Seventy-nine percent $(n=158)$ of participants identified themselves as female. Nineteen percent $(n=9)$ of participants were male. One participant identified as transgender, and one participant chose other and identified as nonconforming. I summarized characteristics of the subjects in Table I. The demographics of the sample reflected the diversity of counselor nationwide, which allowed for some generalization of the results to the target sample population. 
Table 1

\begin{tabular}{lll}
\multicolumn{2}{l}{ Characteristics of Participants $(N=199)$} \\
& $N$ & $\%$ \\
\hline Gender & & \\
Male & 39 & 19 \\
Female & 158 & 79.4 \\
Trans & 1 & 0.5 \\
Other & 1 & 0.5 \\
Not Disclosed & 0 & 0 \\
Years' of Experience & & \\
Less than a year & 3 & 1.5 \\
1-5 & 67 & 42.5 \\
6-9 & 60 & 30.1 \\
10-15 & 36 & 18 \\
16-20 & 16 & 8.5 \\
21-25 & 12 & 6 \\
26-30 & 5 & 2.5 \\
Practice Setting & & \\
Community & 61 & 30.7 \\
Outpatient & 83 & 41.7 \\
Private Practice & 13 & 6.5 \\
Hospital & 8 & 4.0 \\
Residential & 34 & 17.1 \\
Other & & \\
Licensure Status & & 84.9 \\
License & 169 & 15.1 \\
Non-Licensed & 30 &
\end{tabular}

\section{Mean and Standard Deviation of the Dependent Variables}

To score the RKI, I grouped questions into their identified subscale and analyzed

for the mean. The RKI had a mean of 3.37 with a standard deviation of .42 . The subscales for this instrument included the roles and responsibilities in treatment subscale, which had a mean of 4.1 with a standard deviation of .49 . The nonlinearity of treatment sub-scale had a mean of 2.70 with a standard deviation of .62. The self-determination and 
peers in recovery sub-scale had a mean of 3.70 with a standard deviation of 2.37 . The expectations regarding recovery sub-scale had a mean of 2.97 with a standard deviation of .90. These scores appear in Table 2 below.

Table 2

Mean and Standard Deviation of the Dependent Variables

\begin{tabular}{lllll}
\hline Scales and Subscale & Mean & $\begin{array}{l}\text { Standard } \\
\text { Deviation }\end{array}$ & Skewness & Kurtosis \\
\hline $\begin{array}{l}\text { Recovery Knowledge } \\
\text { Inventory }\end{array}$ & 3.37 & .42 & .31 & -.46 \\
$\begin{array}{l}\text { Role and responsibilities in } \\
\text { treatment }\end{array}$ & 4.01 & .49 & .02 & .27 \\
$\begin{array}{l}\text { Non-linearity of recovery } \\
\text { Self-determination and }\end{array}$ & 2.75 & .61 & .33 & .09 \\
peers in recovery & 3.72 & .38 & .49 & .02 \\
$\begin{array}{l}\text { Expectations regarding } \\
\text { recovery }\end{array}$ & 2.98 & .90 & .00 & -.67 \\
& & & & \\
\hline
\end{tabular}

\section{Multiple Regression Analysis}

The purpose of this study was to understand what factors relate to counselors' knowledge and attitudes of the recovery paradigm through survey research methodology. I used a multivariate multiple regression analysis to answer my hypotheses and research questions. Multivariate multiple regression is a statistical method for studying the relationships between multiple dependent variables and one or more independent variables (Field, 2013). Through this analysis, I sought to determine whether independent variables, such as years employed, gender, practice setting, or licensure status correlated 
with the dependent variables, and if so, to identify the potential significance and magnitude of that effect. The outcomes of the analysis appear in Table 3.

Table 3

Multivariate Test $=$ Wilks' Lamba

\begin{tabular}{lllcccc}
\hline Source & Value & $F$ & Hypothesis $d f$ & Error $d f$ & Sig & Partial Eta Sq \\
\hline Gender & .98 & .94 & 4 & 191.00 & .44 & .02 \\
Experience & .98 & .80 & 4 & 191.00 & .52 & .02 \\
Setting & .98 & .93 & 4 & 191.00 & .45 & .02 \\
License & .96 & 2.20 & 4 & 191.00 & .07 & .04 \\
\hline
\end{tabular}

There was no significant difference between genders when considering the four dependent variables (roles and responsibilities in treatment subscale, the nonlinearity of treatment subscale, the self-determination and peers in recovery subscale, the expectations regarding recovery subscale), Wilks' $\Lambda=.98, F(4,191.00)=.94$, partial n squares $=.02$. There was also no significant difference between years of experience when considering the four dependent variables (roles and responsibilities in treatment subscale, the nonlinearity of treatment subscale, the self-determination and peers in recovery subscale, the expectations regarding recovery subscale), Wilks' $\Lambda=.98, F(4,191.00)=$ .80 , partial $\mathrm{n}$ squares $=.02$. Furthermore, there was no significant difference between practice setting when considering the four dependent variables (roles and responsibilities in treatment subscale, the nonlinearity of treatment subscale, the self-determination and peers in recovery subscale, the expectations regarding recovery subscale), Wilks’ $\Lambda=.98$, $F(4,191.00)=.93$, partial $\mathrm{n}$ squares $=.02$. Last, there was no significant difference between licensure status when considering the four dependent variables (roles and responsibilities in treatment subscale, the nonlinearity of treatment subscale, the self- 
determination and peers in recovery subscale, the expectations regarding recovery subscale), Wilks’ $\Lambda=.96, F(4,191.00)=2.99$,partial n squares $=.044$

Table 4

Test between subjects

\begin{tabular}{|c|c|c|c|c|c|c|c|}
\hline Source & DV & & & $d f$ & $M S$ & Sig & Partial Eta Sq \\
\hline \multicolumn{8}{|l|}{ Gender } \\
\hline & Subscale One & .00 & 1 & .00 & .00 & .97 & .00 \\
\hline & Subscale Two & .34 & 1 & .34 & .94 & .34 & .01 \\
\hline & Subscale Three & .15 & 1 & .15 & 1.05 & .31 & .01 \\
\hline & Subscale Four & .16 & 1 & .16 & .20 & .66 & .00 \\
\hline \multicolumn{8}{|c|}{ Experience } \\
\hline & Subscale One & .01 & 1 & .01 & .06 & .81 & .00 \\
\hline & Subscale Two & .01 & 1 & .01 & .00 & .88 & .00 \\
\hline & Subscale Three & .13 & 1 & .13 & .88 & .35 & .01 \\
\hline & Subscale Four & 1.43 & 1 & 1.41 & 1.74 & .19 & .01 \\
\hline \multicolumn{8}{|l|}{ Setting } \\
\hline & Subscale One & .43 & 1 & .43 & 1.83 & .12 & .01 \\
\hline & Subscale Two & .01 & 1 & .01 & .02 & .89 & .01 \\
\hline & Subscale Three & .04 & 1 & .04 & .26 & .61 & .00 \\
\hline & Subscale Four & 1.24 & 1 & 1.24 & 1.52 & .22 & .01 \\
\hline \multicolumn{8}{|l|}{ License } \\
\hline & Subscale One & 1.32 & 1 & 1.32 & 5.64 & $.01 *$ & .03 \\
\hline & Subscale Two & 1.86 & 1 & 1.86 & 5.15 & $.02 *$ & .03 \\
\hline & Subscale Three & .04 & 1 & .04 & .27 & .60 & .00 \\
\hline & Subscale Four & .00 & 1 & .00 & .00 & .97 & .00 \\
\hline
\end{tabular}

Note. ${ }^{*} \mathrm{p}<.05$.

Additional output from my analysis identified the significance of licensure status lies within subscales one and two. Subscale one measures the role and responsibilities in recovery. Subscale two measures the nonlinearity of recovery. I was unable to complete post hoc testing since licensure status has fewer than three groups. 


\section{Summary}

In Chapter 4, I described the data collection process and sample, as explained in Chapter 3 following ethical human research protection and Walden University's IRB procedures. Additionally, I discussed the demographics of the sample and the results, which involved data screening strategies, analysis of the means, descriptive statistics, and the multivariate multiple regression analysis I used to test the hypotheses. Based on the multivariate multiple regression analysis, years of experience, gender, and practice setting did not have a statistically significant correlation or relationship with the four RKI subscales. Licensure, however, was statistically significant regarding subscales one and two but not with subscales three and four. Chapter 5 includes a summary and interpretation of the findings, limitations to this study, and recommendations for further research. 
Chapter 5: Discussion, Conclusions, and Recommendations

\section{Introduction}

My purpose for this quantitative study was to understand what factors contribute to counselors' knowledge and attitudes of the recovery paradigm through survey research methodology. In Chapters 1, 2, and 3 I outlined the problem, reviewed the applicable literature, and explained the research procedures. In chapter 4, I included the sampling frame, data analyses, and the results of the study. After I grouped the questions of the Recovery Knowledge Inventory (RKI) into subscales, I analyzed the data for the mean. When I analyzed the means for each subscale and the overall mean of the RKI, I accepted the the null Furthermore, I used multivariate regression analysis of the independent variables (gender, years of counseling related experiences, professional setting, and licensure status) with the dependent variable (RKI subscales), also had no significant results. Thus, due to no significance, I accepted the null hypothesis. In this chapter, I will further discuss the analysis of the results and limitations of the study. Additionally, I discuss the implications for social change and recommendations for further research.

\section{Interpretation of the Findings}

My purpose for this quantitative study was to understand if certain factors contribute to counselors' knowledge and attitudes of the recovery paradigm. The framework for this study was the recovery model. The recovery model supports collaboration, a working partnership between consumers and stakeholders, and consumer choice (Kidd, Kenny, \& McKinstry, 2015). The recovery model promotes the idea that with hope, meaning, and purpose in life, people with serious mental illness can and do 
recover (Farkas \& Anthony, 2010; Farkas, Anthony, \& Cohen, 1989; SAMHSA,2014). The literature suggested that professional attitudes toward recovery greatly influence recovery outcomes (Kidd, Kenny, \& McKinstry, 2015; Stanhope et al., 2015). Both the wellness paradigm and the recovery paradigm are health-centered rather than diseasecentered and emphasize the role of the consumer in obtaining health and well-being, the two paradigms remain distinct from one another (Sterling, von Esenwein, Ticker, Fricks, \& Dress, 2010). Given the emphasis on counselor ethics and values from professional bodies such as the ACA, exploring the research topic was significant in adding to the counseling literature.

Once I identified the means of each subscale and the overall mean of the RKI, I judged each factor's mean according to a Likert scale (means of 4 and 5 are good and excellent, a means of 3 is okay, and means of 1 and 2 are not so good).Researchers have previously identified the need for continued education and training on the recovery paradigm. The research by Cleary and Dowling (2009) included a sample size of 130 mental health professionals including nurses, psychiatrists, psychologists, social workers, and occupational therapists. Participants worked in community mental health teams and acute admission facilities in Ireland. The results of Clearly and Dowling (2009) study identified subscale three received the highest score of 4.03. Second highest was subscale one with a score of 3.79. Subscale four had a score of 3.08. Last, subscale two had the lowest score of 2.88. Further assessment indicated no significant differences in attitudes and knowledge of recovery based on practice setting. There was a significant difference between respondents with greater or less than 15 years of experience in "nonlinearity of 
the recovery process" (Bedregal et al., 2006, p.1). The respondents with less than 15 years of experience score indicated more favorable attitudes and knowledge then more experienced respondents. The researchers did not find significant differences for the other three subscales. There was a significant difference between genders in the "role of selfdetermination and peers in recovery." The scores indicated women had more favorable attitudes and knowledge than men in recovery. The researchers did not find significant differences for the other three subscales.

When reviewing Cleary and Dowling's (2009) study results to the results of this study, I noted that respondents of both studies scored highest on the third (selfdetermination and peers in recovery) and the first (rules and responsibilities in recovery) subscales. However, score results are reversed between the two studies. Cleary and Dowling's (2009) study results indicating subscale 3 as the highest and subscale 1 as the second highest. The results of this study indicate subscale 1 as having the highest mean and subscale 3 as having the second highest mean. Subscale 1 indicates that counselor have good understanding of the importance of differentiating the role and responsibilities between the counselor and the consumer in the counseling relationship (Bedregal et al.,2006). Subscale 3 indicated that counselor appreciate the need for a counselor in recovery to develop an identify beyond labels such as "patient" or "addict," and having the support of peer in the recovery process (Bedregal et al.,2006). I believe that these outcomes occurred because the concepts behind both subscales are closely related to what is taught through the wellness paradigm. Moreover, the result of my study may also reflect a Rogerian or person-centered approach to counseling which relies of the 
conditions of unconditional positive regard, empathetic understanding, and congruence, an approach that aligns with the recovery paradigm. Both the study results of Cleary and Dowling (2009) and the results of this study indicate that subscale 4 had the third highest means scores and subscale 1 as having the lowest mean scores.

Additionally, Cleary and Dowling's (2009) results indicated significant relationship in scores regarding gender and years of experience. The results from this study did not indicate a difference in means scores in terms of gender or years of experience, but rather licensure status. Cleary and Dowling's (2009) results found that women had more favorable attitudes and knowledge of recovery in their response to subscale one "roles and responsibilities of self-determination and peers in recovery." Cleary and Dowling's (2009) participants identified as 35\% men and 65\% women, where women created the majority of respondents for this study at 79\%. Additionally, Cleary and Dowling's (2009) participants' listed years of experience was more diverse than for this study. The majority of participants in this study, or $70 \%$, had less than 15 years of experience. The results of this study indicated significance between licensure statues and subscale 1: "rule and responsibility in recovery." These results indicated that licensed counselors have more favorable attitude and knowledge than nonlicensed counselors in recovery.

Meehan and Glower (2009) found that the overall means score of the RKI increased after recovery training. In Meehan and Glower's (2009) study, 114 participants were given a pretest/post-test model as part of recovery training. The overall pretest mean score was 3.51. The researchers found that the mean score increased throughout the 
training. A 6-month posttest yielded an overall mean score of 3.89. Participants were mental health professionals living in Queensland, Australia.

The overall means score of this study was 3.37. The overall mean score of this study is approximately .2 lower than the pretest overall means score of Meehan and Glower (2009) study and approximately .5 lower than the six-month posttest. A mean score of 3 is a midrange score on a Likert scale of 1-5, 5 being excellent attitudes and knowledge of recovery. Comparatively speaking, the results of my study indicate that counselors did not score as high as other mental health professionals scored in Meehan and Glower's (2009) study, and through training counselors scores may be improved. Improved scores could directly affect consumer recovery outcomes.

Crowe et al. (2013) used a pretest/posttest method to study the relationship between recovery knowledge, attitudes, and confidence of interns after a 12-month internship. The internship was not associated with changes in the interns' attitudes toward working with mental illness and co-occurring disorders but increased the interns' confidence in their capacity to deliver practices competently (Crow et al., 2013). This change was captured through subscale 1, "roles and responsibilities of self-determination and peers in recovery." The interns' pretest scores were 3.77, and posttest scores were 4.13. Both of these scores are higher than the score of subscale one for this study. Again, training counselors on the recovery paradigm could improve knowledge and attitudes of consumers recovery, thus potentially improving consumer outcomes.

The results of my study are also similar to the results of Bedregal et al. (2006) study. Bedregal et al. (2006) participants included multidisciplinary mental health 
providers from agencies in Connecticut. In Bedregal et al. (2006) study, the highest mean was a 4.15 on subscale three. The second highest subscale being 3.88 on subscale one. Again, the mean scores of this study are lower than those of Bedregals et al. (2006) and the studies previously mentioned indicating the need for counselor training and education.

While the results of this study confirm that the wellness paradigm and recovery paradigm are similar, when comparing mean scores of professionals trained in the recovery paradigm to counselors, scores have shown to be points higher for other mental health professionals indicating a difference in knowledge and attitudes of recovery between counselors and other mental health professionals. The findings from this study support the tenets of my theoretical lens, the recovery model. Counselors can improve their alignment with the recovery model and the ACA code of ethics through continued education and training, as collectively all mental health professional can improve their knowledge and attitudes toward the recovery paradigm and influence greater outcomes for consumers personal recovery.

\section{Limitations of the Study}

Limitations of this study include generalizability, accessibility, time constraints, and the type of inquiry. I limited the sample population to members of the ACA, CESNET-L, the Professional Mental Health Counselors Facebook Group, Social Workers Facebook Group, Psychologists Facebook Group, Action Research Network Facebook Group, Mental Health Counselors Networking Group on Facebook, Online Counseling Referral Network Facebook Group, Counselor/Therapist 
Networking/Consultation Facebook Group. Additionally, participants must have had a masters or doctoral degree in counseling and have practiced within a community setting. The practice settings included community outpatient (county funded), private practice (owned or contracted), hospital, residential facility, or other. The exclusion criteria included mental health practitioners who do not identify themselves as counselors such as social workers, psychologists, case workers, and marriage and family therapists because their expertise differentiates from counselors and would not adequately represent the study population. Counselors who participated in this study required access to a computer and the Internet. Furthermore, participants needed to possess basic technology skills to complete the online survey. The generalizability of the results of my study will include counselors who hold a masters or doctoral degree, work in diverse settings, and have varied amounts of professional experience.

Time constraints are a noted limitation when online surveys are used to obtain participants (Field, 2013). Response rates can be low; therefore, it may take more time to obtain the required sample size. My initial request for participants through the ACA and CESNET-L yielded half the responses I needed to reach my sample size. My initial request was open for 11 weeks. To achieve my sample size in a timely manner, I expanded my request for participants to include professional counseling groups identified through Facebook. I followed the Walden University IRB guidelines and obtained necessary permissions prior to expanding my search.

Quantitative research itself is a limitation, as quantitative research does not offer in-depth responses to research questions. Additionally, participants in this study consisted 
of a self-selected sample. The responses of the participants could have affected the outcome of this study. Another limitation could be the halo effect. The halo effect is a concept that suggests that study participants will respond to survey questions in ways they believe are socially desirable and socially expected (Creswell, 2009).

\section{Recommendations}

Additional research on counselors' knowledge and attitudes of the recovery paradigm is needed. Although this study contributes to counseling research, the counseling profession still needs more research on the study topic. Though similar, the recovery paradigm and the wellness paradigm are not the same. Counselors continue to expand their roles and presence in a variety of setting across the nation. It is counselors' ethical obligation to be knowledgeable in the areas they work and monitor themselves for effectiveness (ACA, 2014). I propose three recommendations for future research that were roused from this study. The first recommendation would be to modify the RKI to reflect terminology more commonly used in the wellness paradigm. I have noticed through this study that counselors and other mental health professional interpret the term recovery as solely referring to the recovery from addiction. By changing the word recovery to wellness, new insight may be into the counselors' knowledge and attitudes of consumer recovery, as well as the relationship between the two paradigms.

My second recommendation would be for future research to include a pretest/posttest model that is tied to specific training on the recovery paradigm. Previous research by Meehan and Glower (2009) found that the overall means score of the RKI increased after recovery training. Again, I refer to the ACA code of ethics in terms 
counselor effectiveness (ACA, 2014). The overall means score of this study was lower than the pretest mean score in Meehan and Glower (2009). The mean scores of their participants improved with education on the recovery paradigm. Improving counselors' knowledge and attitudes of the recovery paradigm would have direct benefit to the consumers served.

My third recommendation would be to explore counselors' knowledge and attitudes of the recovery paradigm through qualitative research. Qualitative research is a means for exploring and understanding a phenomenon (Creswell, 2009; FrankfortNachmias \& Nachmias, 2008). More in-depth research could offer new understanding on counselors' experiences working in recovery-oriented environments yet being trained in wellness.

\section{Implications}

This study may impact both consumers and counselors, and counselors' training and practices, through institutions and continued education. Research on the topic of recovery demonstrates that mental health professionals can have positive or negative impacts on consumers' achievement of personal recovery and quality of life (Berry \& Greenwood, 2015; Wilrycx, et al., 2015).

Research shows that mental health professionals' recovery strategies were positively associated with recovery (Moran et al., 2014). Additionally, the results of Moran et al. (2014) indicated that the more the consumer perceived the professional as using recovery strategies, the more the consumer perceived a working alliance, and the more consumer sense of recovery increased. The results of this study indicated the 
knowledge and attitudes counselors have toward the recovery paradigm impacts outcomes. Counselors' responses in the study by Moran et al. (2014) were similar to the responses from previous research that studied other mental health professionals such as psychiatrists, psychologists, nurses, social workers, and occupational therapists. I concur with previous researchers that continued education and training on the recovery paradigm is necessary. Counselor competency is a professional responsibility of all counselors (ACA, 2014). The impact of improved and continued education on the recovery paradigm would create positive social change and have a direct impact on consumers' attainment of personal recovery and the highest quality of life. The results my study, reflect similar outcomes of previous research. Therefore, as indicated by the results of my study, counselors, like other mental health professional require training and the development of training programs on the recovery paradigm to improve competency and consumer recovery outcomes.

\section{Conclusion}

My purpose for this quantitative study was to understand what factors contribute to counselors' knowledge and attitudes of the recovery paradigm through survey research methodology (Creswell, 2009; Fields, 2013). The recovery paradigm is the directed approach to mental health services in the United States (Cohen et al., 2012). Although trained in wellness, counselors continue to expand their presence in recovery-oriented platforms.

The results of this study identified similar scores or lower scores on the recovery knowledge inventory when compared to previous research outcomes. With similar scores 
and higher scores, previous research indicated a need for continued education and training for mental health clinicians on the recovery paradigm. The knowledge and support of consumer recovery is correlated with higher levels of consumer engagement, satisfaction, symptoms reduction, and greater attained recovery and quality of life (Green et al., 2008). The improvement in counselors' knowledge and attitudes of consumer recovery after training and education reflects common outcomes among other mental health professionals (Cavelti, Homan, \& Vauth, 2016; Green et al., 2008; Wilrycx et al., 2015). Since the literature on this study topic is limited, my recommendations are for further research on counselors' knowledge and attitudes of the recovery paradigm. Future researchers may be interested in changing RKI language and replacing it with wellness language, exploring a pretest/posttest method, or gathering rich data through a qualitative study.

The ACA Code of Ethics, outlines the need for counselors to practice current scientific and evidenced-based practices (ACA, 2014). The code of ethics outlines that counselors only accept positions for which they have training and experience in and take steps to improve their qualifications and effectiveness as necessary (ACA, 2014). Upholding the ACA code of ethics provides a map for counselors to engage in practices that promote the best possible outcomes for consumers. 
References

American Counseling Association (ACA). (2014). 2014 ACA code of ethics. Retrieved from http://www.counseling.org/docs/ethics/2014-aca-code-ofethics.pdf?sfvrsn=4

Anthony, W. A. (1993). Recovery from mental illness: The guiding vision of the mental health service system in the 1990s. Psychosocial Rehabilitation Journal, 16(4), 11-23. doi:10.1037/h0095655

Bedregal, L. E., O'Connell, M., \& Davidson, L. (2006). The Recovery Knowledge Inventory: assessment of mental health staff knowledge and attitudes about recovery. Psychiatric rehabilitation journal, 30(2), 96-103.

Carpenter, J. (2002). Mental health recovery paradigm: Implications for social work. Health \& Social Work, 27(2), 86-94.

Casper, E. S. (2005). The latent variable model of the psychiatric rehabilitation beliefs, goals, and practices scale. Psychiatric rehabilitation journal, 28(3), 260.

Clearly, A., \& Dowling, M. (2009). Knowledge and attitudes of mental health professionals in Ireland to the concept of recovery in mental health: a questionnaire survey. Journal of Psychiatric \& Mental Health Nursing, 16(6), 539-545. doi:10.1111/j.1365-2850.2009.01411.x

Creswell, J. W. (2009). Research design: Qualitative, quantitative, and mixed methods approaches (Laureate Education, Inc., custom ed.). Thousand Oaks, CA: Sage Publications. 
Drake, R. E., \& Whitley, R. (2014). Recovery and severe mental illness: description and analysis. The Canadian Journal of Psychiatry, 59(5), 236-242.

Field, A. (2013). Discovering statistics using IBM SPSS statistics (4th ed.). Thousand Oaks, CA: SAGE.

Frankfort-Nachmias, C., \& Nachmias, D. (2008). Research methods in the social sciences (7th ed.). New York, N.Y.: Worth.

Gaffey, K., Evans, D., \& Walsh, F. (2016). Knowledge and attitudes of Irish Mental Health Professionals to the concept of recovery from mental illness - five years later. Journal of Psychiatric \& Mental Health Nursing, 23(6/7), 387-398. doi:10.1111/jpm.12325

Green, S. B., \& Salkind, N. J. (2014). Using SPSS for Windows and Macintosh: Analyzing and understanding data (7th ed.). Upper Saddle River, NJ: Pearson.

Groves, R. M., Fowler, F. J. Jr., Couper, M. P., Lepkowski, J. M., Singer, E., \& Tourangeau, R. (2009). Survey methodology (2nd ed.). Hoboken, NJ: John Wiley \& Sons.

Harding, C. M., Brooks, G., Ashikaga, T., Stauss, J., \& Breier, A. (1987). The Vermont longitudinal study of persons with severe mental illness. American Journal of Psychiatry, 144, 718-735.

IBM Corporation. (2015). SPSS software. Retrieved from http://www 01.ibm.com/software/analytics/spss/

Meehan, T., \& Glover, H. (2009). Using the recovery knowledge inventory (RKI) to assess the effectiveness of a consumer-led recovery training program for service 
providers. Psychiatric Rehabilitation Journal, 32(3), 223-226.

doi:10.2975/32.3.2009.223.226

Myers, J. E., \& Sweeney, T. J. (2008). Wellness counseling: The evidence base for practice. Journal of Counseling \& Development, 86(4), 482-493.

National Board for Certified Counselors. (2015). Advertise with NBCC. Retrieved from http://www.nbcc.org/

Oliveira-Maia, A. J., Mendonça, C., Pessoa, M. J., Camacho, M., \& Gago, J. (2016). The mental health recovery measure can be used to assess aspects of both customerbased and service-based recovery in the context of severe mental illness.

Frontiers in Psychology, 71-78. doi:10.3389/fpsyg.2016.01679

Ostrow, L., \& Adams, N. (2012). Recovery in the USA: From politics to peer support. International Review of Psychiatry, 24(1), 70-78. doi:10.3109/09540261.2012.659659

Peebles, S. A., Mabe, P. A., Fenley, G., Buckley, P. F., Bruce, T. O., Narasimhan, M., \& ... Williams, E. (2009). Immersing practitioners in the recovery model: An educational program evaluation. Community Mental Health Journal, 45(4), 239245. doi:10.1007/s10597-009-9212-9

Price, J. H., Khubchandani, J., Price, J. A., Whaley, C., \& Bowman, S. (2016). Reducing Premature Mortality in the Mentally Ill Through Health Promotion Programs. Health Promotion Practice, 17(5), 617-622. doi:10.1177/1524839916656146

Razzano, L. A., Jonikas, J. A., Goelitz, M. A., Hamilton, M. M., Marvin, R., JonesMartinez, N., \& ... Cook, J. A. (2010). The recovery education in the academy 
program: Transforming academic curricula with the principles of recovery and self-determination. Psychiatric Rehabilitation Journal, 34(2), 130-136.

Reddy, F., Spauldin, W. D., Jansen, M. A., Menditto, A. A., \& Pickett, S. (2010). Psychologists' roles and opportunities in rehabilitation and recovery for serious mental illness: A survey of council of university directors of clinical psychology (CUDCP) clinical psychology training and doctoral education. Training \& Education in Professional Psychology, 4(4), 254-263. doi:10.1037/a0021457

SAMHSA. (2014). Results from the 2013 national survey on drug use and health: Mental health findings. Retrieved from http://www.samhsa.gov/data/sites/default/files/NSDUHmhfr2013/NSDUHmhfr20 13.pdf

Salgado, J., Deane, F., Crowe, T., \& Oades, L. (2010). Hope and improvements in mental health service providers' recovery attitudes following training. Journal of Mental Health, 19(3), 243-248. doi:10.3109/09638230903531126

Scheyett, A., DeLuca, J., \& Morgan, C. (2013). Recovery in severe mental illnesses: A Literature review of recovery measures. Social Work Research, 37(3), 286-303. Survey Monkey. (2017). How it works. Retrieved from https://www.surveymonkey.com/ Stratford, A., Brophy, L., \& Castle, D. (2012). Integrating recovery-oriented practice into psychiatric registrar training. Australasian Psychiatry, 20(6), 524-526. doi:10.1177/1039856212465349

Swarbrick, M. (2006). A wellness approach. Psychiatric Rehabilitation Journal, 29(4), 311-314. 
Walden University. (2017). Institutional review board for ethical standards in research. Retrieved from http://researchcenter.waldenu.edu/Office-of-Research-Integrityand Compliance.htm

Wilkniss, S., \& Zipple, A. (2009). Evidence-based practices and recovery at thresholds: Transformation of a community psychiatric rehabilitation center. American Journal of Psychiatric Rehabilitation, 12(2), 161-171.

Wilrycx, G., Croon, M., Van den Broek, A., \& van Nieuwenhuizen, C. (2015). Evaluation of a recovery-oriented care training program for mental healthcare professionals: Effects on mental health consumer outcomes. International Journal of Social Psychiatry, 61(2), 164-173. doi:10.1177/0020764014537638 
Appendix A: Demographic Information Questionnaire

1.) I identify my gender as:

1. Male

2. Female

3. Trans*

4. Other, please specify

5. Prefer not to disclose

2.) Please specify your years of experience working as a counselor (example 5 years). The reported number should only include years after graduating from a master's level counseling program:

3.) Please select your practice setting from the following options:

1. Community Outpatient (county funded)

2. Private Practice (owned or contracted)

3. Hospital

4. Residential

5. Other, please specify

4.) Please select your licensure status:

1. Non- Licensed

2. Licensed 


\section{Appendix B: Recovery Knowledge Inventory}

What is your understanding of the recovery process? Please rate the following items using the scale below:

Please rate the following items on a scale of 1 to 5 :

$\begin{array}{lllll}1 & 2 & 3 & 4 & 5\end{array}$

Strongly Agree Strongly Disagree Disagree Not Sure Agree

1. The concept of recovery is equally relevant to all phases of treatment. 12345

2. People receiving psychiatric/substance abuse treatment are unlikely to be able to decide their own treatment and rehabilitation goals. 12345

3. All professionals should encourage clients to take risks in the pursuit of recovery. 12 345

4. Symptom management is the first step toward recovery from mental illness/substance abuse. 12345

5. Not everyone is capable of actively participating in the recovery process. 12345

6. People with mental illness/substance abuse should not be burdened with the responsibilities of everyday life. 12345

7. Recovery in serious mental illness/substance abuse is achieved by following a prescribed set of procedures. 12345

8. The pursuit of hobbies and leisure activities is important for recovery. 12345

9. It is the responsibility of professionals to protect their clients against possible failures and disappointments. 12345 
10. Only people who are clinically stable should be involved in making decisions about their care. 12345

11. Recovery is not as relevant for those who are actively psychotic or abusing substances. 12345

12. Defining who one is, apart from his/her illness/condition, is an essential component of recovery. 12345

13. It is often harmful to have too high of expectations for clients. 12345

14. There is little that professionals can do to help a person recover if he/she is not ready to accept his/her illness/condition or need for treatment. 12345

15. Recovery is characterized by a person making gradual steps forward without major steps back. 12345

16. Symptom reduction is an essential component of recovery. 12345

17. Expectations and hope for recovery should be adjusted according to the severity of a person's illness/condition. 12345 
APPENDIX C: Permission to use the RKI

Received 8/12/2017 at 4:30pm

Dear Kathleen:

You do have my permission to use the RKI.

I am attaching two documents: One is the 20-item RKI form and the other document contains scoring of items, empirically derived dimensions, item narrative, and theoretically derived domains.

The way to score this instrument is to get means for each domain. Then, judge each factor's mean according to Likert scale (means of 4 and 5 are good and excellent, a mean of three is okay, and means of one and two are not so good).

Do not forget to change scores on items that are reversed (i.e., a score of one will be a five, a two will be a four, a three will remain the same, a four will be a two, and a score of five will be a one).

If you have any more questions about the RKI, please do not hesitate to contact me. Also, if you plan to use our instrument, we will appreciate if you share your results with us.

Good luck!

Luis

August 2, 2017

Dear Dr.,

I am a doctoral student from Walden University writing my dissertation titled "Counselors' Knowledge and Attitudes of Mental Health Recovery", under the direction of my dissertation committee chaired by Dr. Corinne Bridges.

I would like your permission to use the Recovery Knowledge Inventory in my research study. I would like to use and print your survey under the following conditions:

- I will use the surveys only for my research study and will not sell or use it with any compensated or curriculum development activities.

- I will include the copyright statement on all copies of the instrument. 
- I will send a copy of my completed research study to your attention upon completion of the study.

If these are acceptable terms and conditions, please indicate so by replying to me. Sincerely,

Kathleen

Doctoral Candidate 


\section{APPENDIX D: ACA Participant Request}

\section{Discussion Group Etiquette}

Calls for participants for studies are allowed and must be posted in the Call for Study Participants community. Calls for participants posted in other discussion threads will be moved to the designated community.

- Include a signature tag on all messages. Include your name, affiliation, location.

- State concisely and clearly the topic of your comments in the subject line. This allows members to respond more appropriately to your posting and makes it easier for members to search the archives by subject.

- Include only the relevant portions of the original message in your reply. Delete any header information, and put your response before the original posting.

- When replying to messages, do not reply to the entire list if a reply is directed at a single individual. Replying to the individual may be more appropriate. Replies of a personal nature should not be sent to the group.

- Only send a message to the entire list when it contains information that everyone can benefit from.

- Send messages such as "thanks for the information" or "me, too" to individuals-not to the entire list. Do this by using the "Reply to Sender" link to the left of every message.

- Do not send administrative messages, such as requests for removal from the list. Instead, use the web interface to change your settings or to remove yourself from a list. If you are changing e-mail addresses, you do not need to remove yourself from the list and rejoin under your new email address. Simply change your settings.

- Warn other list subscribers of lengthy messages either in the subject line or at the beginning of the message body with a line that says "Long Message."

- Keep in mind the following: Be nice. Assume good intent. Own your own words. Keep it relevant. 


\section{APPEXDIX E: CESNET- L Information}

CESNET-L is being used more and more to launch surveys for people doing research in Counselor Education and Supervision. As listowner I am happy to see that researchers see the value of the membership of this list and seek their opinion for various issues. I have thought of a few tips that you should consider before posting your research to CESNET-L

In general, netiquette suggests that you ask the permission of the listowner before you post a survey to a listserv. It is helpful that your request to post include the information that is below in the "In your post:" section along with an anticipated posting schedule. In your survey:

1. How long is your survey? Have someone who is totally unfamiliar with your survey take it and time them. Double it... We often underestimate the amount of time it takes people to take these. In our desire to make our research question broad, we over extend the survey. it says 5-10 minutes, I stop at 5-10 minutes...

2. How many variables do you have and what is the 'power' need of your instrument? If your inventory has so many variables that you need over 3500 respondents to show significance you are in trouble from the start. Begging for more people to take the survey won't help in this case, and just looks desperate.

3. Members of CESNET-L are typically counselor educators, and students who are emerging counselor educators. If the subject pool for your study are left-handed male clients with the diagnosis of trichotillamania who are currently receiving treatment, 
CESNET-L is not the list for your survey. Think about the subject pool you are seeking before you post.

4. I have no demographics on the population of membership of CESNET-L so I have nothing for you to compare your sample with to the population of membership. If you need to know the larger population of the group are sampling, CESNET-L is not the place for you.

5. Make sure your demographics permit anonymity, if that is what you are promising. (Asking if you are a Caucasian male, who teaches multicultural counseling, at a doctoral granting institution in Northeast Ohio, pretty much calls ME out.) Also, there is a tendency for folks to ask about demographics that they don't need. All those extra variables you add into you project raises the power of the sample that you will need to show significance and the $\mathrm{N}$ that you will need.

6. Avoid begging for subjects for your study. It is considered spam on a listserv and I will drop your ability to post

7. Set up a reasonable schedule for a second and third (final) request. Consider it similar to mail-out surveys. The Internet makes it easy for folks to "pester until you get enough people" and I am not sure that is a good research methodology. What does it say about the participant you get on the fifth request? Those who violate the third request rule are now subject to removal from the list. 
In your post:

1.Include everything that you would include in a cover letter if you were mailing the survey out. This generally means..

a. Your Name

b. Your contact information, both email and direct (phone).

c. Your advisor and their contact information (This is now a requirement!!! Research advisors please make sure you preview the posting and the posting schedule.)

d. Your institutional affiliation

e. An indication that it has passed the institutional review board

f. Purpose of the study

g. Reason you are doing it (to fulfill the degree requirements for ... )

h. How the results will be used

i. Permission to withdraw at anytime

2. Make sure that your survey link is correct. Test it in a personal email sent to yourself or someone else before posting it to the list. 


\section{APPENDIX F}

\section{Dear Administrator,}

My name is Kathleen Ruscitto, and I am a doctoral candidate at Walden University. I am contacting you to request permission to post a link to my survey on your professional page. I have include a copy of my proposed post below. Please let me know if you have further questions.

Sincerely,

Kathleen Ruscitto, Doctoral Candidate

\section{Dear Counselor:}

You are invited to participate in a survey that I will be conducting as a doctoral candidate in the $\mathrm{PhD}$ Program in Counselor Education and Supervision at Walden University. This study is about counselors' knowledge and attitudes regarding the recovery paradigm. You are asked to participate in this study if you hold a master's degree or higher in counseling and counsel individuals 18 years of age or older. If you decided to participle in this study, you will be asked to complete an online survey. The survey should take approximately 510 minutes to complete.

There is no direct benefit to you for participating. Being in this type of study involves some risk of the minor discomforts that can be encountered in daily life, such as fatigue. Being in this study would not pose risk to your safety or wellbeing. Your participation may contribute to the education and professional development of counselors. Your participation in this survey is voluntary. The survey is anonymous. None of these questions will identify you as an individual. All responses will be reported in the aggregate and the results of the study will be used for my doctoral dissertation, scholarly presentations, or articles for publication. Survey Monkey offers password protection and encryption software to store data.

You may contact me, Kathleen Ruscitto if you have any questions about the study. If you have questions before you make your decision, please contact me. If you want to talk privately about your rights as a participant, you can call the Research Participant Advocate at my university at 612-312- 1210 Walden University's approval number for this study is 04-10-18-0509448 and it expires on April 9th, 2019.

If you feel you understand the study well enough to make a decision about your participation, please indicate your consent by clicking the link below or coping it into your browser.

https://www.surveymonkey.com/r/MDFMHKR

Thank you for your consideration. 
Sincerely,

Kathleen Ruscitto, PhD Candidate, Walden University 